\title{
Role of Glycogenolysis in Memory and Learning: Regulation by Noradrenaline, Serotonin and ATP
}

\author{
Marie E. Gibbs * \\ Drug Discovery Biology, Monash Institute of Pharmaceutical Sciences, Monash University, Parkville, VIC, Australia
}

OPEN ACCESS

Edited by:

Ye Chen,

Navy Medical Research Center, USA

Reviewed by:

Mauro DiNuzzo,

Historical Museum of Physics and Enrico Fermi Center for Study

and Research, Italy

Frank Kirchhoff,

Saarland University, Germany

*Correspondence:

Marie E. Gibbs

marie.gibbs@monash.edu;

mariegibbs1@gmail.com

Received: 14 October 2015

Accepted: 17 December 2015

Published: 19 January 2016

Citation:

Gibbs ME (2016) Role of Glycogenolysis in Memory and Learning: Regulation by Noradrenaline, Serotonin and ATP.

Front. Integr. Neurosci. 9:70. doi: 10.3389/fnint.2015.00070
This paper reviews the role played by glycogen breakdown (glycogenolysis) and glycogen re-synthesis in memory processing in two different chick brain regions, (1) the hippocampus and (2) the avian equivalent of the mammalian cortex, the intermediate medial mesopallium (IMM). Memory processing is regulated by the neuromodulators noradrenaline and serotonin soon after training glycogen breakdown and re-synthesis. In day-old domestic chicks, memory formation is dependent on the breakdown of glycogen (glycogenolysis) at three specific times during the first 60 min after learning (around 2.5, 30, and $55 \mathrm{~min}$ ). The chicks learn to discriminate in a single trial between beads of two colors and tastes. Inhibition of glycogen breakdown by the inhibitor of glycogen phosphorylase 1,4-dideoxy-1,4-imino-D-arabinitol (DAB) given at specific times prior to the formation of long-term memory prevents memory forming. Noradrenergic stimulation of cultured chicken astrocytes by a selective $\beta_{2}$-adrenergic (AR) agonist reduces glycogen levels and we believe that in vivo this triggers memory consolidation at the second stage of glycogenolysis. Serotonin acting at $5-\mathrm{HT}_{2 B}$ receptors acts on the first stage, but not on the second. We have shown that noradrenaline, acting via post-synaptic $\alpha_{2}$-ARs, is also responsible for the synthesis of glycogen and our experiments suggest that there is a readily accessible labile pool of glycogen in astrocytes which is depleted within 10 min if glycogen synthesis is inhibited. Endogenous ATP promotion of memory consolidation at 2.5 and $30 \mathrm{~min}$ is also dependent on glycogen breakdown. ATP acts at $\mathrm{P}_{2} \mathrm{Y}_{1}$ receptors and the action of thrombin suggests that it causes the release of internal calcium $\left(\left[\mathrm{Ca}^{2+}\right]_{\mathrm{i}}\right)$ in astrocytes. Glutamate and GABA, the primary neurotransmitters in the brain, cannot be synthesized in neurons de novo and neurons rely on astrocytic glutamate synthesis, requiring glycogenolysis.

Keywords: astrocytes, glycogen re-synthesis, noradrenaline, ATP, serotonin, memory processing, consolidation, day-old chickens

\section{INTRODUCTION}

The major fuel for all cells in the brain is glucose and both astrocytes and neurons metabolize glucose via glycolysis and oxidative phosphorylation. Neuronal transmission of information is undoubtedly important for memory but astrocytes are also critically involved in memory processing. Memory is dependent on metabolic functions including $\mathrm{Na} / \mathrm{K}$-ATPase activity and 
glucose uptake, which occur in both neurons and astrocytes. It is also reliant on glycogen breakdown and re-synthesis. It is recognized that glycogen has an important role in the brain (e.g., Brown, 2004; Brown and Ransom, 2007; Hertz et al., 2007; Oz et al., 2007; Morgenthaler et al., 2009). Normally only astrocytes can store glucose as glycogen. Glycogen in the brain is stable and has slow turnover under resting conditions (Watanabe and Passonneau, 1973; Choi et al., 2003; Oz et al., 2007). Glycogen is unlikely to be acting solely as a slowly available energy source. The breakdown of glycogen increases substantially during sensory activation in the brain (Swanson, 1992; Swanson et al., 1992; Cruz and Dienel, 2002) and it appears to have an active role in astrocytic function. It is necessary for memory formation in both chickens and rodents (O’Dowd et al., 1994; Gibbs et al., 2006; Suzuki et al., 2011; Newman et al., 2011; Duran et al., 2013). Both Suzuki et al. and Newman et al. assumed that glycogen-derived lactate is used as a metabolic fuel by neurons after release from astrocytes via the astrocytic monocarboxylate transporters MCT 1 and 4 and uptake in neurons via the neuronal MCT 2 (i.e., operation of the astrocyte-to-neuron lactate shuttle (ANLS)) suggested by Pellerin et al. (1998) and Pellerin and Magistretti (2012). However, a recent study by Tadi et al. (2015) showed that learning in mice increased expression of MCT 1 and 4 without affecting MCT 2. Thus astrocytic lactate release is important for learning but it is doubtful whether any neuronal uptake occurs. Moreover convincing evidence has recently been obtained for activitydependent glucose phosphorylation in neurons (Patel et al., 2014), which focuses attention on recently discovered signaling functions of extracellular lactate (Tang et al., 2014; Bergersen, 2015). In this context it is interesting that the lactate signaling demonstrated by Tang et al. (2014) like memory in the chicken is abolished not only by the glycogenolysis inhibitor DAB (see below) but also by D-lactate (Gibbs and Hertz, 2008). The action of these and other drugs used in the studies to be reviewed are summarized in Table $\mathbf{1 .}$

\section{MEMORY FORMATION IN THE CHICKEN FOLLOWING ONE-TRIAL DISCRIMINATED AVOIDANCE LEARNING}

The experiments described in this review use avoidance training in the day-old chick. Chicks are precocious and can discriminate between colors soon after hatch, and they do so after a single $10 \mathrm{~s}$ learning experience. At training a red bead is tainted with a compound of bitter taste (methyl anthranilate) and presented to the chick for $10 \mathrm{~s}$. They peck at this bead once or twice (Figure 1A) before registering the bitter taste and turning away in disgust (Figure 1B). On test after a predetermined interval they are then presented with clean red (Figure 1C) and blue (Figure 1D) beads, each for $10 \mathrm{~s}$. The chickens will avoid the second (untainted) red bead when presented, but they will continue to peck when presented with a neutral blue bead. Memory is measured as the ratio of pecks at red and blue beads on test. A high discrimination ratio reflects a good memory and avoidance of pecking at the red bead, whereas a discrimination ratio close to 0.5 reflects an increased rate of pecking at the red bead- such that red and blue beads are pecked at equally on the 10 s test (for details see Gibbs and Summers, 2002a; Gibbs et al., 2008d). It is not uncommon for chicks to give up to 10 pecks at the blue bead, and when they have forgotten they can give up to 10 pecks on the clean red bead.

The chicks are kept in pairs and used in groups of 20, or more recently, in groups of 16 chicks. The data from chicks not pecking the blue bead on test or not pecking the red bead on training are excluded from the data analysis at the completion of the experiment. Each data point on the behavioral graphs represents a single group of chicks with generally no more than 2-3 chicks excluded on the basis on not training or avoiding the blue bead, i.e., $N \geq 13-14$ when the original number in the group was 16 . The very short training period enables exact timing of biochemical events correlated with learning.

The bead is either strongly aversive, i.e., the bitter taste is caused by application of $100 \%$ anthranilate, or weakly aversive when anthranilate is diluted to $20 \%$ with alcohol. When separate groups of chicks are tested at defined periods post-training after strongly reinforced training three stages of memory are revealed, and the memory remains for days, indicating that this corresponds to normal learning. However, even in normal learning there are brief periods of low discrimination ratios measured on testing at 15 or at $55 \mathrm{~min}$. With weak reinforcement, with the exception of the test at $15 \mathrm{~min}$ after training, the memory is good on tests up to $30 \mathrm{~min}$ after which memory disappears (Figure 1E).

Based on the demonstration of different biochemical events (Gibbs and $\mathrm{Ng}, 1977$ ) we have defined three stages of memory consolidation during normal learning : short-term (STM)-lasting for $10 \mathrm{~min}$ intermediate term memory (ITM), which has two different stages, ITMA between 20 and $30 \mathrm{~min}$ and ITMB between 30 and $50 \mathrm{~min}$. The transition is normally triggered by neuromodulatory transmitters, including noradrenaline and serotonin, as will be reviewed here. Weakly reinforced learning (Figure 1E) includes ITMA but not ITMB, another indication that these two stages depend upon different metabolic events. The advantage of studying weakly reinforced learning is that it can be converted to normal learning by different procedures, providing information on possible underlying mechanisms. Normal learning can on the other hand be disrupted by other interventions, again providing clues about the underlying events. Accordingly, both types of learning will be discussed in this review.

Drugs are injected into the hippocampus in $1 \mu$ l volumes (Gibbs et al., 2008a; Figure 1F) or in 5 or $10 \mu \mathrm{l}$ volumes into the intermediate medial mesopallium (IMM), a cortical integration area in the avian brain serving the same functions as the cortex in mammals (Puelles et al., 2000; Reiner et al., 2004; Jarvis et al., 2005). This area of the brain has been traditionally used for studies on memory (see Gibbs, 2008; Gibbs et al., 2008d). By injecting different groups of chicks at different times, we have been able to determine when memory is vulnerable to either inhibition in the case of strongly reinforced training or 
TABLE 1 | Individual effects of drugs on glycogenolysis and memory in imm and hippocampus (Hp).

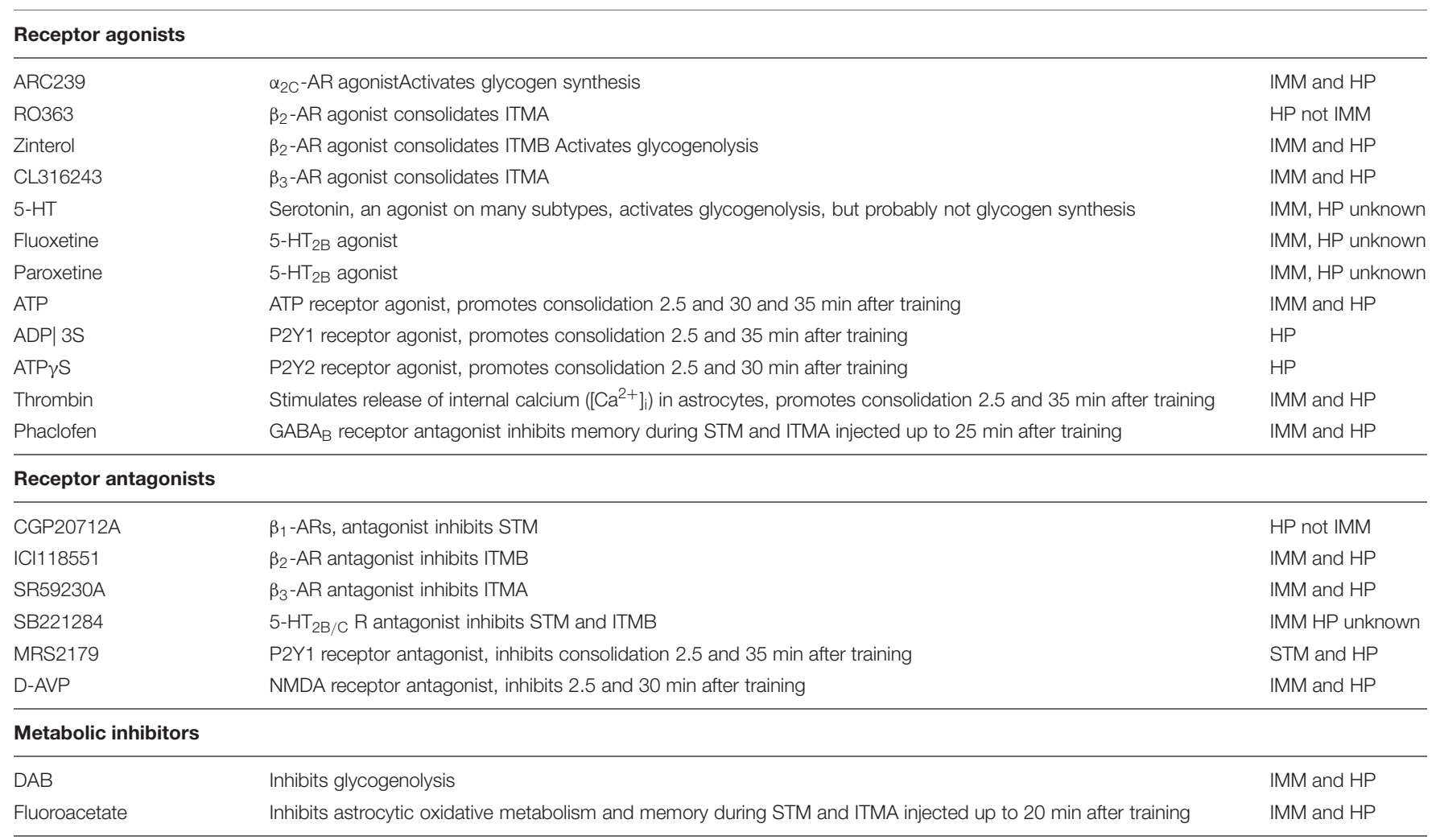

consolidation in the case of weakly reinforced training. When injections of inhibitory agents are made after strongly reinforced training, memory is poor on test either at 120 min or at specified times after training; consolidation of weakly reinforced training maintains memory after ITMA. Figure 1F shows details of the injection procedure for hippocampal injections and it can be seen that tissue damage due to the injection is minimal (Gibbs et al., 2008a). All procedures reviewed here have been approved by the Monash University Animal Ethics Committee and comply with the 1997 Australian Code of Practice for the care and use of animals for scientific purposes. All efforts were made to minimize both the suffering and the number of animals used. Chicks were killed at the completion of each experiment by $\mathrm{CO}_{2}$ inhalation.

Key points of our findings are (1) the involvement of glycogen in memory processing and in synthesis of glutamate, a neurotransmitter essential for learning (Riedel et al., 2003) and long-term potentiation, LTP (Bashir et al., 1993), (2) the role of neuromodulators in glycogenolysis, glycogen synthesis and learning, and (3) mechanisms by which the neuromodulators influence glycogen storage and breakdown and thus the processes during learning which are glycogenolysis-dependent. A crucial role of glycogenolysis in glutamate synthesis (Figure 2) was first shown in chick brain during learning (Gibbs et al., 2007) and its role in support of glutamatergic transmission was confirmed in co-cultures of neurons and astrocytes (Sickmann et al., 2009) and in the mouse brain (Sickmann et al., 2012). That synthesis of transmitter glutamate as well as return of previously released transmitter glutamate depends on astrocytic metabolism has been known for a long time (reviewed by
Gibbs et al., 2008b; Hertz, 2013; Hertz and Rothman, 2015), however that the astrocytic-neuronal flux carrying glutamate from astrocytes to neurons equals the rate of total neuronal glucose consumption (or 75\% of total gray matter oxygen uptake) has only been established more recently (Sibson et al., 1998; Rothman et al., 2011). This shows the intensity of the astrocyticneuronal interactions required during learning.

\section{MEMORY FORMATION REQUIRES THE BREAKDOWN OF GLYCOGEN}

Measurement of the change in glycogen levels, expressed as \% of pretraining levels revealed two periods where total forebrain levels decreased and later rose to former pretraining levels (O’Dowd et al., 1994; Hertz et al., 2003). There is a large, rapid decrease 2.5 min after training where glycogen levels remain low for $10 \mathrm{~min}$ and then return to previous levels within $5 \mathrm{~min}$ (Figure 3A). There is a second transient decrease at $55 \mathrm{~min}$. This fits wth the turnover of brain glycogen increasing during activation of brain tissue (Swanson et al., 1992; Dienel et al., 2003, 2007). A third tendency toward a decrease at $30 \mathrm{~min}$ is not significant.

The importance of the breakdown of glycogen for learning is seen when an inhibitor of glycogenolysis or glycogen breakdown is injected into the forebrain at different times after training. The glycogen phosphorylase inhibitor DAB (Andersen et al., 1999; Fosgerau et al., 2000) blocks glycogenolysis but is known not to affect glycolysis. 

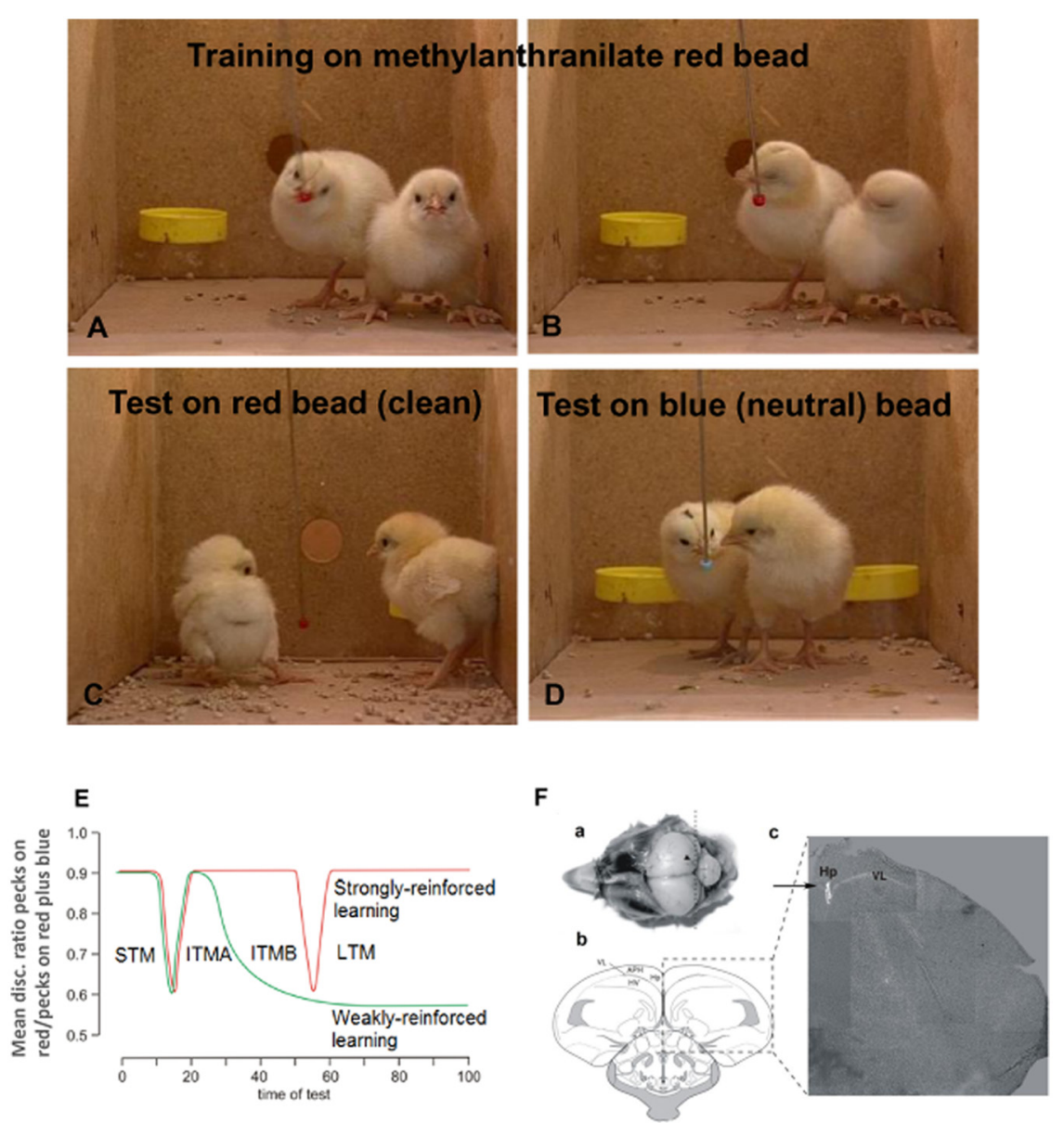

FIGURE 1 | Memory model established from single trial learning in day-old chicks. Prior to training chicks are presented once with clean red and blue beads to ensure they will peck at beads of both colors. For training they are presented for $10 \mathrm{sec}$ with a red bead lightly coated in methyl anthranilate (A). They peck at this once or twice before registering the bitter taste and turning away in disgust (B). On test they are then presented with clean red (C) and blue (D) beads, each for $10 \mathrm{~s}$ and the number of pecks on each counted using an electronic counter and converted by computer to discrimination ratios (DRs). Perfect learning equals a DR of 1 , and complete forgetting or inhibition of learning a DR of 0.5. Normally the DR after unimpaired learning is $\sim 0.9$. The chicks are kept in pairs and 8-10 pairs are included in the group used in each experiment, which allows reliable determination of significance. Each data point on subsequent graphs represents one group. (E) Memory stages following strongly reinforced (red line) after exposure to undiluted aversant and weakly reinforced training (green line) after exposure to diluted aversant. The loss of labile, weakly reinforced memory coincides with the transition between two phases of intermediate memory (ITM A and B) 30 min post-training. Drugs are used to inhibit strongly reinforced learning or rescue weakly reinforced learning, as indicated by memory retained 120 min after training. (F) Illustration of injection for hippocampal administration of drugs. (a) Image of head with scull removed and injection site indicated by arrowhead. Dotted line indicates coronal section presented in panels (b) and (c). see Gibbs et al., 2008a for details. (1F from Gibbs et al., 2008a).

In chicks where $\mathrm{DAB}$ was injected into IMM 5 min before training or $55 \mathrm{~min}$ after training, there was very poor memory $2 \mathrm{~h}$ later, but injection between 25 and $45 \mathrm{~min}$ after training also decreased memory (Figure 3B). When does this memory deficit occur? The early blockade of glycogenolysis 5 min prior to training leads to an inability to retrieve memory from shortterm storage until after 10 min after training, with no amnestic effect being seen between 20 and $30 \mathrm{~min}$ (Figure 3C); we concluded therefore that memory retrieval throughout the first part of intermediate memory (ITMA) does not depends on glycogenolysis, but does so on tests from $40 \mathrm{~min}$ on. Effects occur early and some of the consequences appear during STM, not ITMA but later during ITMB. However, DAB has effects on memory beyond this time. When memory is monitored after injections made 25 min after training, memory loss is seen at the earliest test made $35 \mathrm{~min}$ after training, i.e., $10 \mathrm{~min}$ after injection and with injections $55 \mathrm{~min}$ after training, memory is lost $15 \mathrm{~min}$ later - the earliest time tested (Gibbs et al., 2006).

DAB injected into the hippocampus also leads to memory loss (Gibbs et al., 2008a). However, the pattern of susceptibility in the hippocampus is not not the same as in IMM (see Figure 3D). There are three important times where there is coincidence -5 , 25 , and 55 min post- training, but there are differences between the two brain areas. DAB inhibits in the hippocampus when injected during ITMA in contrast to IMM, whereas during ITMB (30-50 min after training) DAB is inhibitory in the cortex but not in the hippocampus. When DAB is injected into the hippocampus $5 \mathrm{~min}$ before training, memory is present tested at $20 \mathrm{~min}$ 


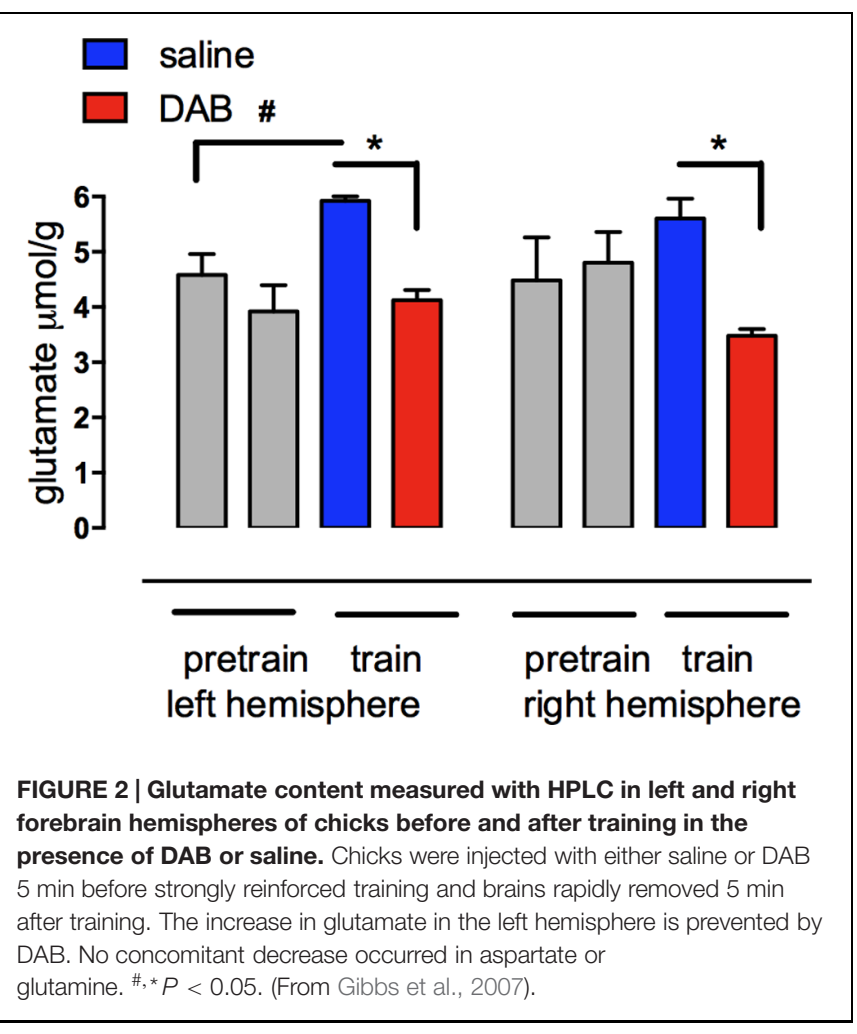

but as with IMM injection memory is absent when chicks are tested 5 and 120 min after training (Gibbs et al., 2008a). DAB does not appear to produce a long acting inhibition of glycogen phosphorylase, since when it is injected $10 \mathrm{~min}$ before training it has no effect on memory. These data and results mentioned below suggest that there is a time lag of 5-10 min before glycogenolysis is significantly inhibited.

The breakdown of glycogen is clearly important for learning. Two of the susceptible periods when long-term memory is prevented occur when DAB is administered during STM (0-10 min post-training) or at the end of intermediate memory (ITMB) 55 min after training, and both periods correlate with the changes in glycogen levels in the forebrain. However, there is a second period when memory is sensitive to DAB (around 20-25 min post-training) but is not associated with a significant decrease in glycogen content, suggesting that glycogen synthesis may be going on at this time, offsetting the inhibitory effect on glycogenolysis. This is supported by the observation that an inhibitor of glycogen synthesis inhibits memory 10-20 and 40-60 min after training (see below).

What is the trigger for glycogenolysis? Evidence is presented here for the involvement of noradrenaline, serotonin and ATP in the breakdown of glycogen for memory processing.

\section{NORADRENERGIC TRIGGER OF GLYCOGENOLYSIS}

There is evidence that glycogenolysis is stimulated by noradrenaline (Magistretti, 1988; Quach et al., 1988; Subbarao and Hertz, 1990), and in the chicken, via the $\beta_{2}$-adrenergic receptor (Gibbs et al., 2006) at the time of transition between the first and second phases of intermediate memory, i.e., around 25-30 min after training. Noradrenaline acts on two $\alpha$ and three $\beta$ receptor subtypes, and in extensive studies we have shown that it can do so via all five subtypes (Gibbs and Summers, 2002a, 2005 ) with effects differentiated by time and brain location.

Injected into the cortex, noradrenaline promotes formation of memory after weakly- reinforced training by activation of $\beta_{2}$ - and $\beta_{3}$-adrenergic receptors as well as by $\alpha_{1}$-ARs. Consolidation of weakly reinforced training is achieved with injection of either $\beta_{2}$ (zinterol) or $\beta_{3}$-AR (CL316243) receptor agonists (Figure 4A). Both agonists consolidate when injected at any time up to 30 min after training with the exception of a lesser effect with injection given at 15 min post-training. In the avian brain there is a predominance of $\beta_{2}$-ARs (see Gibbs et al., 2008a), whereas in the mammalian brain mainly the $\beta_{1}$ - subtype of the receptor is expressed (Quach et al., 1978). However, the $\beta_{1}$ AR agonist RO363 was unable to promote consolidation at any of the times injected into IMM (Gibbs and Summers, 2002a) but there are $\beta_{1}$ - AR effects on memory in other brain areas such as the Medial Striatum and the hippocampus (see below). The specific antagonist for the $\beta_{2}$-AR (ICI 118551) and for the $\beta_{3}$-AR (SR59230) both inhibited strongly reinforced learning when injected $5 \mathrm{~min}$ after training, with the $\beta_{2}$-AR antagonist inhibiting up to $25 \mathrm{~min}$ after training, i.e., over the duration of ITMA, but memory was spared when the antagonists were given 5 min before training (Figure 4B).

In the hippocampus injection of the $\beta$-AR agonists promoted consolidation of weakly reinforced training; zinterol and CL316243 both promoted consolidation although with slightly different timing compared to that seen in the IMM. In addition, the $\beta_{1}$-AR agonist RO363 also promoted consolidation during STM and the antagonist CGP20712A inhibited strongly reinforced training over the same time course (Figures 4C,D). Varying the time of injection clearly shows that both the agonists and antagonists had different memory response patterns in the hippocampus and the IMM.

Although the $\beta_{2}$-AR agonist in IMM can consolidate memory injected up to $25 \mathrm{~min}$ post-training (Figure 4A), the time at which the antagonist is effective has a close correlation with the time when DAB is ineffective (Figure 3B). In the hippocampus glycogenolysis is critical for underwriting the STM and ITMA memory periods as well as at 55 min post-training (Figure 3D). The $\beta_{2}$-AR agonist was only effective for a short time when injected during ITMA, whereas the $\beta_{3}$-ARs were active during STM and ITMA. The $\beta_{1}$-AR agonists promoted consolidation with injection during STM only (Figure 4C).

Behavioral experiments to confirm that glycogenolysis is associated with $\beta_{2}$-adrenoceptors involved challenging the selective agonists with a weak dose of DAB or saline. A dose level of $\mathrm{DAB}$ that was not sufficient to block memory itself was injected at a time when it has been shown not to affect memory. In the cortical area (IMM) $\beta_{2}$ - and $\beta_{3}-A R$ agonists were injected $25 \mathrm{~min}$ after weakly reinforced training when they normally promote consolidation. DAB reduced the ability of zinterol to consolidate memory (Figure 5A), but 

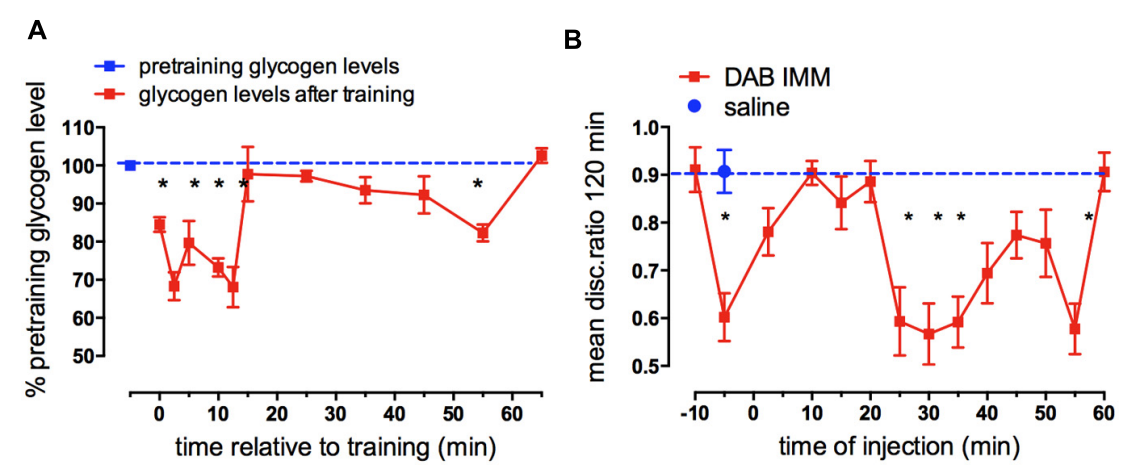

C

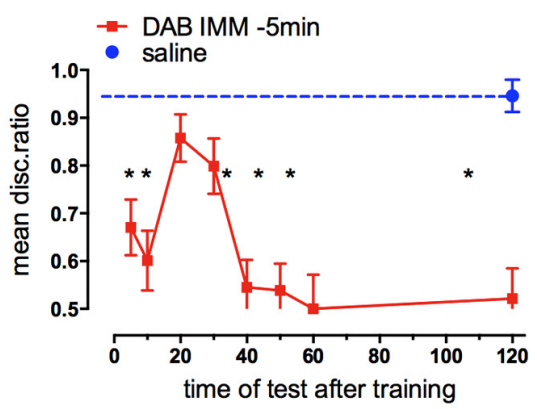

D

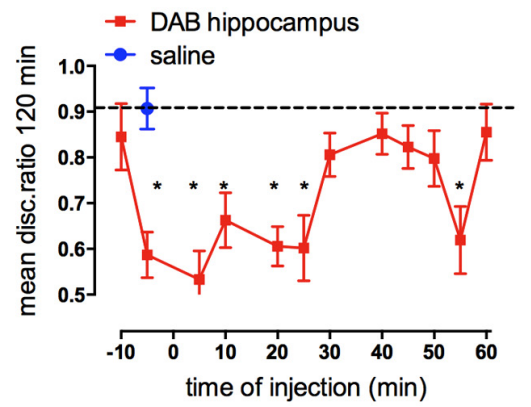

FIGURE 3 | Glycogen levels after training in chick forebrain and effect on memory consolidation of inhibition of glycogen breakdown. (A) Glycogen levels in combined left and right hemispheres after training compared with the glycogen content at pre-training. Glycogen was measured as described by Lo et al. (1970) with minor modifications. Brains were excised and transferred to pre-weighted tubes and their weight determined by the increase in weight. After digestion of the tissue, glycogen was precipitated by the addition of $95 \%$ ethanol, hydrolyzed to glucose in a phenol-sulphuric acid solution and the absorbance measured at $490 \mathrm{~nm}$ and calibrated by aid of a standard glucose curve (From O'Dowd et al., 1994; Hertz et al., 2003). (B) Times of injection of DAB into IMM after strongly reinforced training showing those times at which memory processing requires glycogen breakdown; (C) Times of test after strongly reinforced training following DAB injection 5 min before training revealing when memory is affected by DAB; (D) Times of injection of DAB into the hippocampus following strongly reinforced training. (From Gibbs et al., 2007, 2008b). In this figure and all subsequent graphs the dashed line represents saline control value for strongly reinforced training (high DR) or weakly reinforced training (DR approaching 0.5$)^{\star} P<0.05$.

had no effect on the ability of the CL316243 to consolidate memory (Figure 5B). In the hippocampus, a low dose of DAB did not affect the ability of CL316243 or the $\beta_{1}$-AR agonist RO363 to consolidate memory, but as in IMM, DAB reduced the ability of zinterol to promote consolidation (Gibbs et al., 2008a). Since DAB prevents activation-induced glycogen breakdown and decreases memory, we conclude that glycogen breakdown achieved by stimulation of $\beta_{2}$-ARs is necessary for memory.

\section{GLYCOGEN CONTENT AND SYNTHESIS IN CULTURED CHICKEN ASTROCYTES}

The effects on glycogen levels measured in chick astrocyte primary cultures, in the presence of $\mathrm{DAB}$ or in the presence of zinterol (with $\mathrm{DAB}$ or saline added $20 \mathrm{~min}$ prior to zinterol exposure) are shown in Figure 6A. As can be seen DAB did not alter the basal glycogen levels but it did prevent the zinterolinduced decrease in glycogen level (Gibbs et al., 2006) but had no significant effect in the presence of the $\beta_{3}$-adrenergic antagonist CL316243.
If stimulation of noradrenergic $\beta_{2}$-ARs stimulates memory consolidation via the breakdown of glycogen with no dramatic decrease in glycogen levels (at $30 \mathrm{~min}$ post-training), it is likely that there is some cellular mechanism to stimulate the synthesis of glycogen. This increased synthesis is achieved by noradrenaline released from neurons stimulating astrocytic $\alpha_{2}$ ARs (post-junctional receptors; Hertz et al., 2007; Hutchinson et al., 2011; Gibbs and Hutchinson, 2012). At the same time $\beta_{3^{-}}$ adrenergic stimulation increased uptake of glucose, securing the glucose presence needed for the synthesis of glycogen (Gibbs and Summers, 2002a,b; Gibbs et al., 2008c).

Noradrenaline increased glycogen formation (total ${ }^{14} \mathrm{C}$ incorporation) in astrocytic culture (Hutchinson et al., 2008, 2011). This was not inhibited by the $\beta_{1}-/ \beta_{2}-A R$ antagonist propranolol nor by the $\beta_{3}-\mathrm{AR}$ antagonist SR59230A, suggesting that the effect of noradrenaline to increase glycogen turnover is not mediated by $\beta$-ARs (Hutchinson et al., 2011). Insulin was used as the positive control (Figure 6B). When the effects on glycogen levels were compared, insulin and clonidine significantly increased glycogen levels but the other agonists had no effect (Figure 6C). A timecourse experiment with noradrenaline, isoprenaline and zinterol demonstrated 


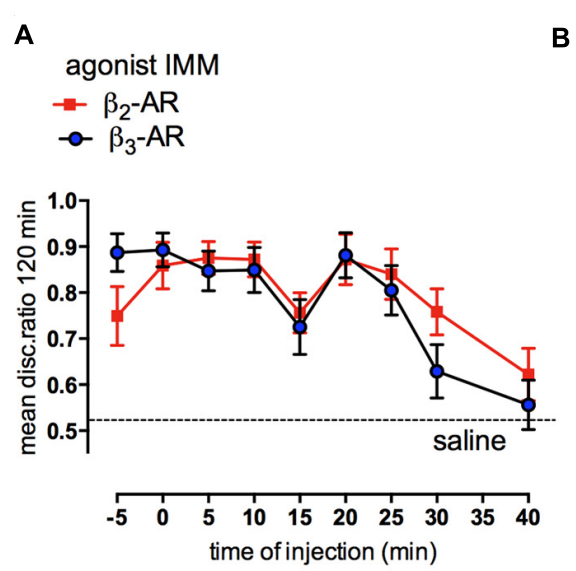

C

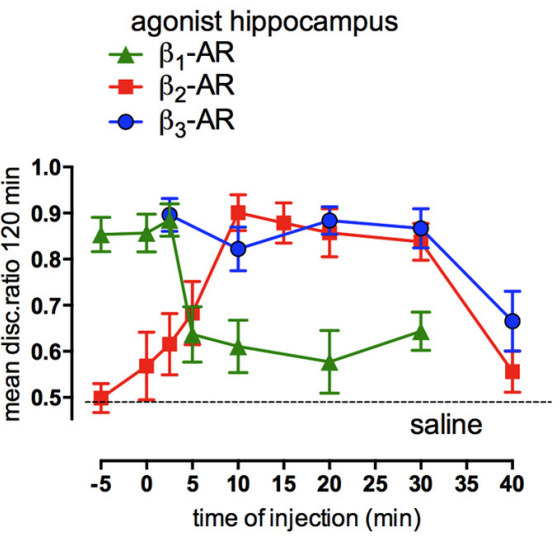

$$
\begin{aligned}
& \text { antagonist IMM } \\
& =-\beta_{2} \text {-AR } \\
& -0-\beta_{3} \text {-AR }
\end{aligned}
$$

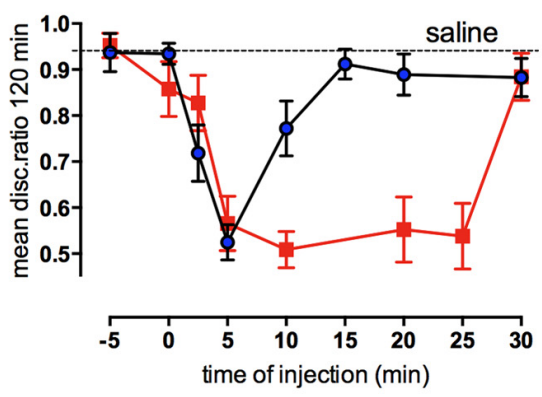

D

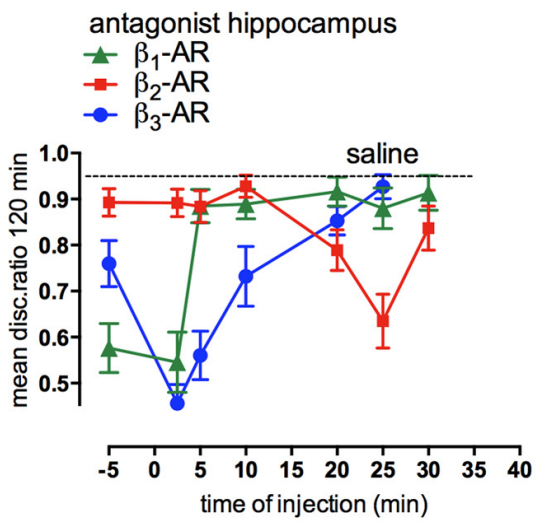

FIGURE 4 | Involvement of $\beta$-adrenoceptors in weakly- and strongly reinforced memory in both avian cortex (IMM) and hippocampus. Injections of selective $\beta$-AR agonists at different times after weakly reinforced training in IMM (A) or hippocampus (C) and of selective antagonists for $\beta$-ARs in IMM (B) or hippocampus (D) after strongly reinforced learning. Memory tested 120 min after training. (From Gibbs, 2008).

significantly decreased glycogen levels following 5 and $10 \mathrm{~min}$ of stimulation (Hutchinson et al., 2008). In experiments where noradrenaline and subtype selective agonists were incubated with astrocytes, only noradrenaline and the $\alpha_{2}$-AR agonist clonidine increased glycogen synthesis measured as total ${ }^{14} \mathrm{C}$ incorporation (\% of basal) into glycogen, whereas the $\beta$-AR agonists had no significant effect. Noradrenaline stimulates glycogenolysis and formation of cAMP in similar cultures of astrocytes (O'Dowd et al., 1995), consistent with the glycogenolytic mechanism shown in Figure 7A.

The $\alpha_{2}$-AR agonist clonidine activates both $\alpha_{2 A^{-}}$and $\alpha_{2 C^{-}}$ ARs and both are present in areas of the brain important for memory processing (Scheinin et al., 1994; Hutchinson et al., 2011). AR $\alpha_{2 \mathrm{~A}}$-and $\alpha_{2 \mathrm{C}}$-AR subtypes are found both pre and post-synaptically on neurons as well as post-junctionally on astrocytes (Enkvist et al., 1989; Aoki, 1992; Lee et al., 1998a,b; Hertz et al., 2010). In chick astrocytes clonidine stimulation of glycogen synthesis was blocked by the $\alpha_{2 C^{-}}$ AR subtype selective agonist ARC239 (Gibbs and Hutchinson, 2012). $\alpha_{2}$-Adrenergic stimulation activates glycogen synthesis by stimulation of the AKT pathway and subsequent downregulation of GSK (Figure 7B). This is consistent with the

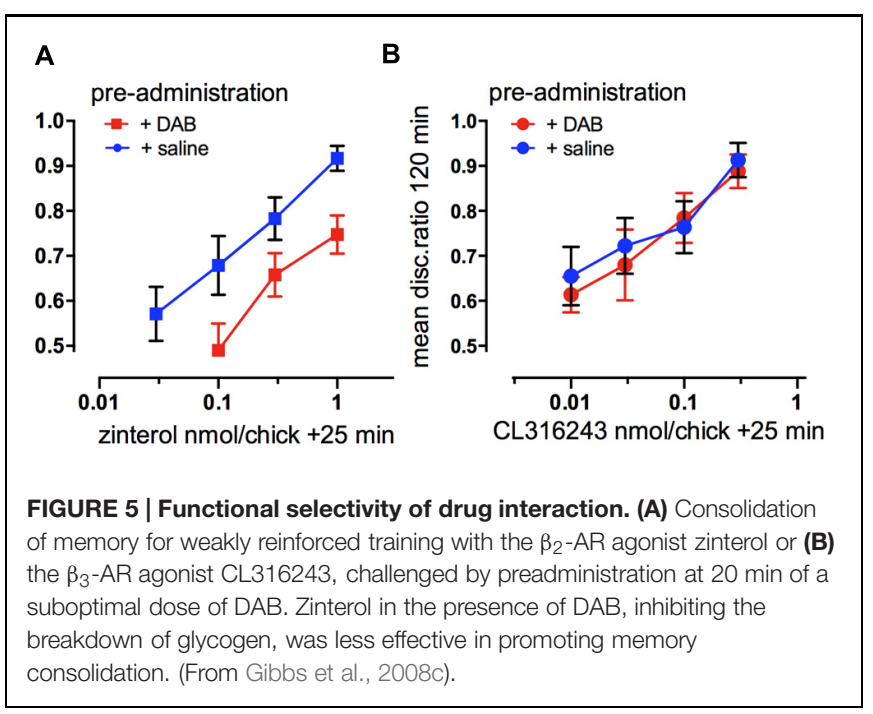

observations that the potent $\alpha_{2}$-AR agonist, dexmedetomidine induces ERK phosphorylation both in cultured astrocytes and in brain slices, but not in cultured neurons (Li et al., 2008; Du et al., 


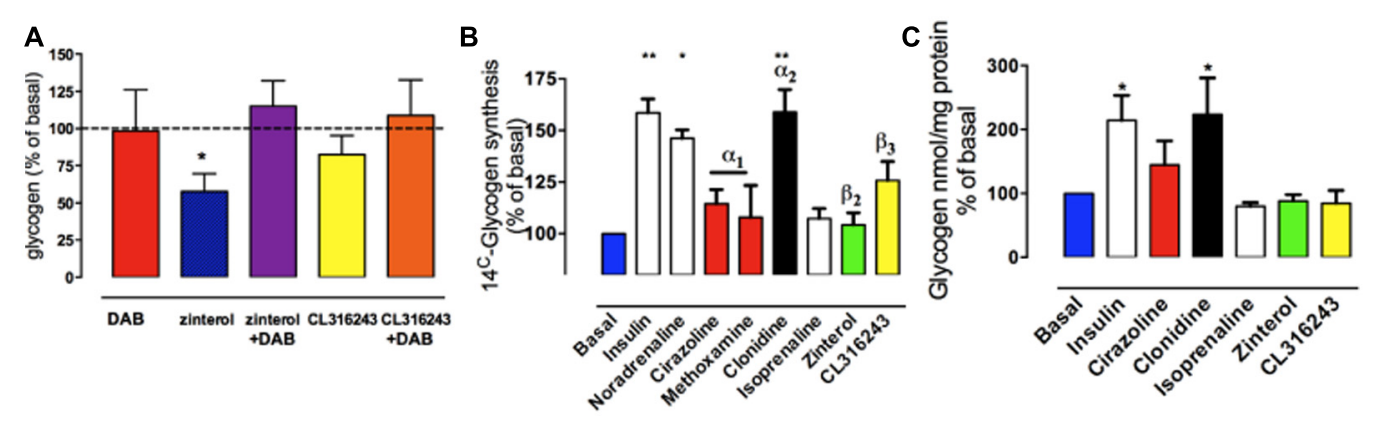

FIGURE 6 | The effect of adrenoceptor agonists on glycogen levels turnover and new synthesis in cultured astrocytes from chick forebrain. (A) Astrocytes were incubated for $2 \mathrm{~h}$ under basal conditions with no drug added, or for $2 \mathrm{~h}$ in the presence of zinterol or CL316243. DAB was added 20 min prior to the $2 \mathrm{~h}$ incubation (adapted from from Gibbs et al., 2006). (B) Glycogen synthesis assessed by [ $\left.{ }^{14} \mathrm{C}\right]$-glucose incorporation into glycogen in response to $3 \mathrm{hr}$ stimulation with AR agonists, noradrenaline or insulin. (C) Glycogen levels expressed as \% of basal after incubation with AR agonists or insulin. * $P<0.05$; ${ }^{\star *} P<0.001$. (From Hutchinson et al., 2011).

2009), and that the ERK and AKT pathways interact in astrocytes (Dai et al., 2013).

\section{EFFECT OF ARC239 INHIBITION OF $\alpha_{2 C}$ ARS ON MEMORY PROCESSING AND COMPARISON WITH DAB TIMECOURSE}

Inhibition of the synthesis of new glycogen, caused by injection of the selective $\alpha_{2 C}-\mathrm{AR}$ antagonist ARC239 into IMM revealed a clear time-dependence. Memory at $120 \mathrm{~min}$ was inhibited by ARC239 injected at two time periods after training, (i) when injected 10-20 and (ii) when injected 40-50 min after strongly reinforced training (Figure 8A). On the other hand, preventing glycogen breakdown with $\mathrm{DAB}$, inhibited memory when injected at three different times: $5 \mathrm{~min}$ before, $25-35 \mathrm{~min}$ after and at $55 \mathrm{~min}$ after training in IMM. The effects of ARC239 and $\mathrm{DAB}$ mirror each other but with a lag time of about 10 min (Hertz and Gibbs, 2009). ARC239 prevented memory at quite discrete time points, which suggests that its inhibitory action is not sustained for long periods in the brain. In the presence of ARC239 there is insufficient accessible glycogen, so $\beta_{2}$-ARs although activated cannot induce glycogenolysis and promote consolidation. Since noradrenaline will activate $\alpha_{2}$-AR as well as $\beta_{2}$-ARs at the same time, any measurement of glycogen levels will reflect the net balance between synthesis and degradation.

There is a slow turnover of glycogen during resting conditions in the brain (Brown, 2004; Oz et al., 2007), but it can obviously be accelerated to underwrite memory processing in the hippocampus and cortex, as illustrated in Figure 3. DAB is only active in the brain for a short time period as when injected 10 min before training DAB had no effect on memory. In agreement with this idea, $\mathrm{DAB}$ injected $5 \mathrm{~min}$ prior to training memory is only shown to be effective when first tested $5 \mathrm{~min}$ after training, suggesting that it does not remain active in the brain for long and therefore only acts on memory processes very close to the time of injection, even though the consequences appear later.
Our data clearly show that glycogen has an active role in astrocytic function. This may in turn also influence neuronal metabolism because glycogenolysis may inhibit astrocytic glucose consumption and thereby make more glucose available for neurons (DiNuzzo et al., 2012, 2015). Since glycogen turnover is slow under resting conditions, the question arises as to how fast it can be recruited in cells and are there readily accessible stores with fast turnover in brain regions important for memory. It is possible that high turnover could occur in specific brain regions during neural activation. Glycogen phosphorylase can be activated within seconds and is stimulated during various behavioral activities (Walling et al., 2006). In chick astrocyte cultures, we have shown an initial decrease in glycogen levels after 5-10 min of incubation with noradrenaline, this decrease is then followed by an increase in glycogen levels (Hutchinson et al., 2011). The fall in glycogen levels, but not the later increase, also occurs with incubation with zinterol. These biochemical results suggest that the onset of breakdown of glycogen can occur quickly.

We designed experiments where the glycogen synthesis inhibitor ARC239 was challenged with zinterol (increasing glycogenolysis and promoting weakly reinforced learning) in two different paradigms (Gibbs and Hutchinson, 2012; Figures 8B,C) to ask two questions: firstly, can prevention of glycogen resynthesis reduce glycogen levels sufficiently so that zinterol is unable to promote weakly reinforced learning, and at when does this occur after training? When we prevented glycogen synthesis by injecting ARC239, given 5 min before training, zinterol was able to promote consolidation given either immediately or $5 \mathrm{~min}$ after training, but it was unable to promote memory when given later than this, at 10, 15, or 20 min after training (Figure 8B), although zinterol will normally do so at these times. These results suggest that the ARC239-mediated inhibition following its injection $5 \mathrm{~min}$ before training took $10 \mathrm{~min}$ to reduce the readily available glycogen stores.

Secondly, we asked by what mechanisms and at what times can inhibition of glycogen synthesis affect the ability of zinterol to promote consolidation after weakly reinforced training? Zinterol was injected $20 \mathrm{~min}$ after training to promote consolidation 
A

noradrenaline

$\downarrow$

$\beta_{2}-\mathrm{AR}$

फीणि

Gs

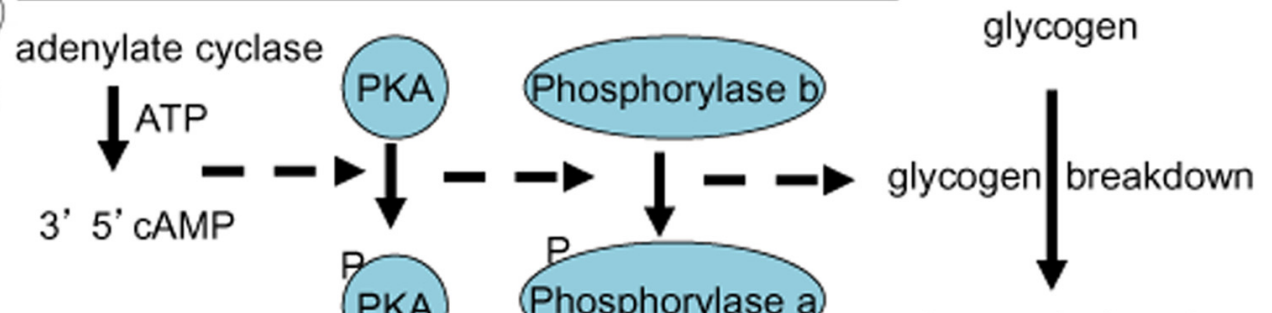

PKA

glucose-1-phosphate

B

Noradrenaline

Clonidine

$\alpha_{2}-A R$
Noradrenaline, clonidine and insulin increase glycogen synthesis but cirazoline, isoprenaline, zinterol, CL316243 and AICAR do not

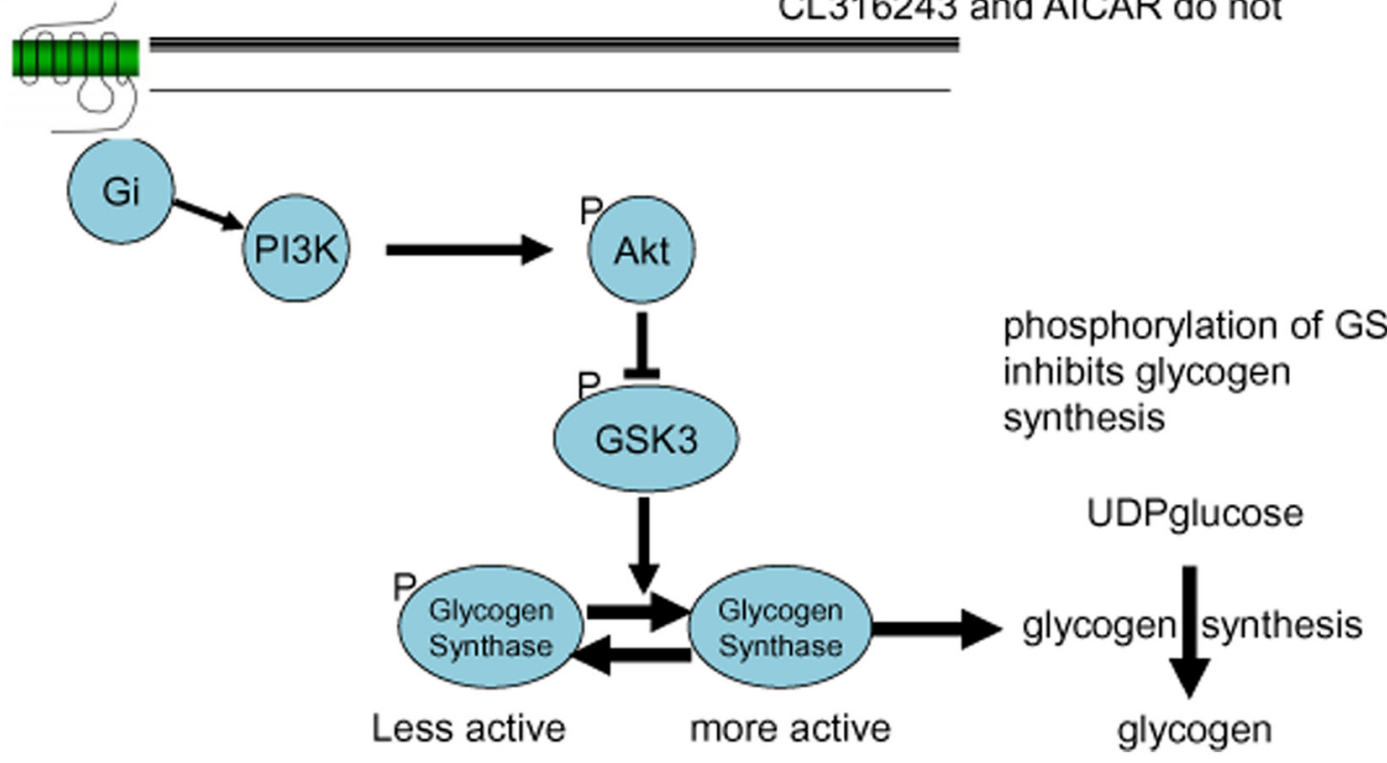

FIGURE 7 | Noradrenergic signaling stimulating glycogenolysis (A) or glycogen synthesis (B). (A) $\beta_{2}$-Adrenergic $G_{S}-$ mediated formation of cAMP and phosphorylation of proteinkinase A (PKA) leads to conversion (phosphorylation ) of phosphorylase b to the active phosphorylase a, which stimulates glycogen breakdown (conversion of glycogen to glucose-1-phosphate). (B) $\alpha_{2}$-Adrenergic $\mathrm{G}_{\mathrm{i}}$-mediated stimulation of the PI3K-AKT pathway leads to phosphorylation of glycogen synthase kinase (GSK) and dephosphorylation of glycogen synthase, which stimulates glycogen synthesis (incorporation of UDPglucose into glycogen).

and ARC239 at times between 5 min before and 15 min after training (i.e., $20-5$ min before zinterol) prevented the $\beta_{2}$-AR agonist promoting consolidation at all times except 5 min before training (Figure 8C). ARC239 given up to $10 \mathrm{~min}$ before zinterol prevented it from promoting consolidation. These results again suggest that depletion of accessible glycogen stores takes place quickly, i.e., within $10 \mathrm{~min}$ of injection.

\section{Serotonin and Glycogenolysis}

Serotonin is another neuromodulatory transmitter that promotes memory consolidation (Gibbs and Hertz, 2014). Like noradrenaline, serotonin activates glycogenolysis in brain tissue and in astrocytes (Quach et al., 1982; Cambray-Deakin et al., 1988; Magistretti, 1988; Chen et al., 1995; Kong et al., 2002; Darvesh and Gudelsky, 2003). Although the $\beta_{2}$-AR activation 

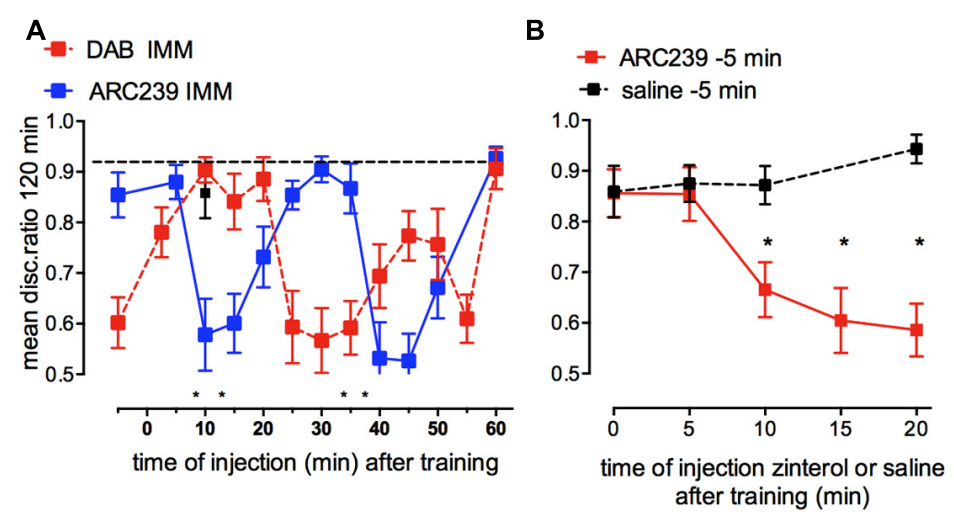

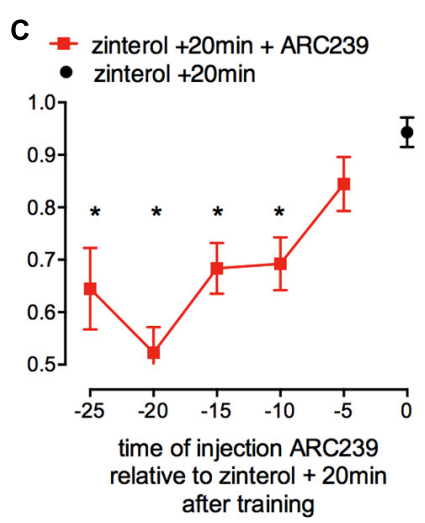

FIGURE 8 | Effect of inhibition of glycogen re-synthesis by the $\alpha_{2 B}$ C-AR antagonist ARC239 on strongly reinforced memory and challenges to inhibition of re-synthesis by $\boldsymbol{\beta}_{\mathbf{2}}$-AR stimulation (glycogen breakdown) and vice versa. (A) ARC239 was injected into IMM at different times after training. The timing of the effect of ARC239 is compared with that of DAB (From Gibbs et al., 2008b; Hertz and Gibbs, 2009). (B) ARC239 or saline were injected 5 min before weakly reinforced training and zinterol injected into different groups at various times after training. Inhibiting re-synthesis of glycogen prevented $\beta_{2}$-AR stimulation from promoting memory consolidation up to 10 min prior to zinterol injection. Normal learning is indicated by black squares. (C) Zinterol was injected into all groups 20 min after weakly reinforced training and ARC239 had been injected at times from 25 to 5 min before zinterol (i.e., from 5 min before to 15 min after training). ${ }^{*} P<0.05$. (From Gibbs and Hutchinson, 2012).

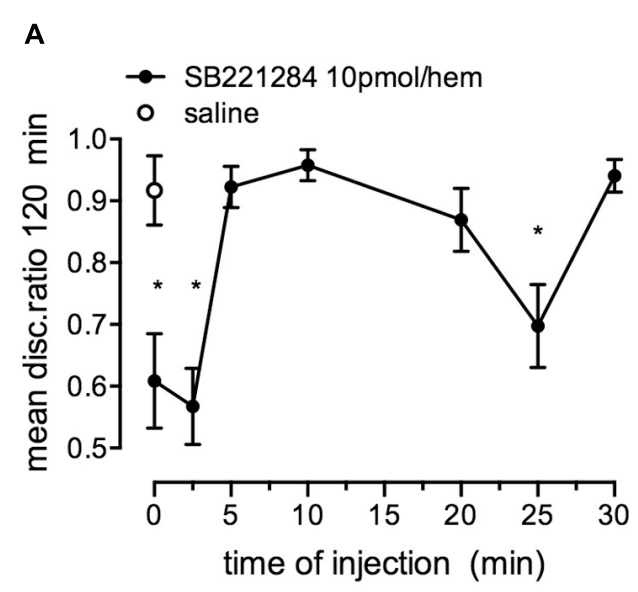

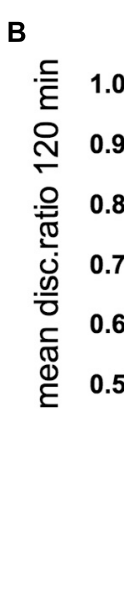

FIGURE 9 | Effect of the selective 5- $\mathbf{H T}_{\mathbf{2 B} / \mathbf{C}}$ receptor antagonist SB221284 on strongly reinforced memory. (A) Time of injection of SB221284 following strongly reinforced training. (B) Ability of the inhibitor DAB to prevent consolidation of weakly reinforced memory. A suboptimal dose of DAB was given either before or 15 min after training, serotonin was given 2.5 or 20 min after training. DAB only interfered with serotonin induced consolidation at the early period. ${ }^{\star} P<0.05$. (From Gibbs and Hertz, 2014).

appears to be the signal leading to the second glycogenolytic period in IMM, noradrenaline is not implicated in the first period close to training. Serotonin has effects on memory in the chick dependent on the dose. Low doses of serotonin promote memory consolidation when injected up to $25 \mathrm{~min}$ after weakly reinforced training whereas high doses inhibit memory (Gibbs and Hertz, 2014). Serotonin thus appears to act on at least two different 5HT receptors during learning stimulating a high affinity serotonin receptor, identified below as the $5 \mathrm{HT}_{2 \mathrm{~B}}$ receptor and inhibiting a lower-affinity serotonin receptor, possibly a $5-\mathrm{HT}_{1}$ receptor.

Strongly reinforced memory is inhibited by the selective $5 \mathrm{HT}_{2 \mathrm{~B}, \mathrm{C}}$ antagonist SB221284 injected immediately, 2.5 or
25 min after (Figure 9A). Conversely, weakly reinforced learning can be rescued by administration of serotonin (Figure 9B). In contrast to the $\beta_{2}$-AR involvement, it is only during the first period where SB221284 inhibits (2.5 min after training) that the rescue by serotonin is challenged by a sub-optimal dose of DAB. In contrast, during the second glycogenolytic period where serotonin plays only a minor role, memory is not significantly affected when $D A B$ is administered together with serotonin (Figure 9B). On the other hand the $5-\mathrm{HT}_{2 \mathrm{~B}}$ agonists fluoxetine and paroxetine (Li et al., 2008; Diaz et al., 2012) can consolidate weakly reinforced learning. It is interesting that fluoxetine and paroxetine which are better known as serotonin-specific 
antidepressants (SSRIs) also consolidate weakly reinforced learning in the chicken (Gibbs and Hertz, 2014). Fluoxetine also increases glycogenolysis in cultured astrocytes (Chen et al., 1995) by a $5-\mathrm{HT}_{2 \mathrm{~B}}$ receptor-mediated effect (Kong et al., 2002).

\section{ATP AND GLYCOGENOLYSIS}

As with the neurotransmitters, noradrenaline and serotonin, memory consolidation is also modulated by endogenous adenosine triphosphate (ATP) acting at purinergic receptors in the hippocampus (Gibbs et al., 2011) and in the cortex (IMM; Cronin et al., 2011). ATP is important for communication between neuronal and glial circuits and is released from both neurons and astrocytes (Fields and Burnstock, 2006; North and Verkhratsky, 2006). ATP released from astrocytes acts as a widespread gliotransmitter, triggering, and maintaining calcium signaling and calcium oscillations (Bowser and Khakh, 2004; Burnstock, 2007; Zorec et al., 2012). Release of transmitter ATP from cultured astrocytes is inhibited by DAB (Hertz et al., 2014b; Xu et al., 2014). On the other hand ATP is also known to trigger glycogenolysis (Hertz et al., 2015c). ATP injected into either the hippocampus (Figure 10A) or IMM promoted consolidation of weakly reinforced training at two time periods: $0-2.5$ and $25-30$ min post-training. The two nonhydrolyzable agonist analogs, ATP $\gamma \mathrm{S}$ and ADP $\beta S$ (Figure 10B) produced similar but not identical effects on memory time courses, in particular with ADP $\beta$ S promoting consolidation at 35 but not at $30 \mathrm{~min}$, whereas ATP $\gamma \mathrm{S}$ promoted consolidation when injected at 30 but not at $35 \mathrm{~min}$. Challenge to the action of ADP $\beta S$ by the selective ADP $\beta S$ antagonist MRS2179 showed that it acts via purinergic $\mathrm{P}_{2} \mathrm{Y}_{1}$ receptors (Gibbs et al., 2011).

Astrocytes are a major source of the released ATP in hippocampal slices in rodents (Bowser and Khakh, 2007), and evidence suggesting astrocytes are the source of the ATP promoting memory comes from the effect of thrombin on memory processing. Thrombin selectively activates calcium release from intracellular stores in astrocytes (Bowser and Khakh, 2004) and thrombin injected into IMM (Gibbs and Bowser, 2010) or the hippocampus (Figure 10C; Gibbs et al., 2011) like ADP $\beta S$, promoted memory consolidation when injected at 2.5 and 35 min after training. These results strongly suggest that astrocytes are the source of the ATP facilitating memory. Thrombin consolidation could also be successfully challenged by a low dose of the P2Y1 antagonist MRS2179. The inhibitory effect of fluoroacetate, which inhibits astrocytic oxidative metabolism, also confirms astrocytic involvement in promotion of memory by ATP (Gibbs and Bowser, 2009). Neither ADP $\beta$ S nor thrombin were able to promote consolidation with prior administration of fluoroactate (Gibbs et al., 2011).

Further support for astrocytic involvement in purinergic memory formation comes from the successful challenge by $\mathrm{DAB}$ of both $\mathrm{ADP} \beta S$ and thrombin rescue of weakly reinforced learning (Figures 10D,E). DAB did not challenge ATP $\gamma \mathrm{S}$ suggesting that the source of the ATP mimicked by ATP $\gamma$ S could therefore be neurons, which co-release ATP with glutamate or noradrenaline (Burnstock, 2007). Incubation of astrocytes with ATP $\gamma S$ or ADP $\beta S$ resulted in an increase in intracellular calcium $\left[\mathrm{Ca}^{2+}\right]_{i}$, with the effect of $\mathrm{ADP} \beta S$ being blocked by fluoroacetate and also by the P2Y1 antagonist, again implicating a specific role for astrocytic $\mathrm{P} 2 \mathrm{Y} 1$ receptors in the calcium response. We suggested that the source of the ATP itself acting on neural P2Y1 receptors is most likely astrocytes, since thrombin selectively increases $\left[\mathrm{Ca}^{2+}\right]_{i}$ in astrocytes but not in neurons (Bowser and Khakh, 2004). Astrocytic $\left[\mathrm{Ca}^{2+}\right]_{\mathrm{i}}$ must accordingly play an important role in the consolidation of short-term to long-term memory through activation of astrocytic P2Y1 receptors (Gibbs et al., 2011). An increase in $\left[\mathrm{Ca}^{2+}\right]_{i}$ is also a prerequisite for stimulation of glycogenolysis (Hertz et al., 2015c). An important pathway for entry of $\mathrm{Ca}^{2+}$ is store-operated $\mathrm{Ca}^{2+}$ channels, and store-operated $\mathrm{Ca}^{2+}$ entry (SOCE) triggers astrocytic glycogenolysis in cortical astrocyte cultures (Müller et al., 2014). Accordingly administration of DAB reduces the amount of $\mathrm{Ca}^{2+}$ loaded into the sarco/endoplasmic reticulum.

\section{GLYCOGEN FACILITATION OF DE NOVO SYNTHESIS OF GLUTAMATE USED FOR MEMORY PROCESSING AND INVOLVEMENT WITH ASTROCYTIC Na,K-ATPase ACTIVITY}

It was shown earlier (Figure 2) that glycogenolysis is essential for the production of glutamate and thus also of its metabolite GABA, two important neurotransmitters. Glutamate is supplied by astrocytes to neurons, which are unable to synthesize glutamate de novo as will be discussed below. If the breakdown of glycogen in astrocytes is compromised, then so is neural transmission (Hertz et al., 2003; Hertz and Zielke, 2004; Sickmann et al., 2009). This process would require relatively rapid turnover of glycogen in vivo.

Astrocytic glycogenolysis supports increased glutamate and glutamine synthesis at both 5 min (Figure 2; Hertz et al., 2003; Gibbs et al., 2007) and probably also after 30 min after training. Both these times are consistent with the times at which glutamate is released in trained chickens (Daisley et al., 1998; Daisley and Rose, 2002). The reduction in glycogen levels in the chick forebrain coincides with a transient increase in glutamate in the left forebrain over the first $5 \mathrm{~min}$ after training, and since there is no concomitant decrease in aspartate or the glutamate precursor glutamine, it indicates de novo synthesis of glutamate (Hertz et al., 2003; Gibbs et al., 2007). The importance of glycogenolysis for glutamate synthesis has been confirmed in the rat (Sickmann et al., 2012).

Since glycogen is responsible for the increased glutamate content in neurons occurring at specific times during memory consolidation, it would be expected that glutamine as a glutamate precursor should be able to rescue memory impairment caused by $\mathrm{DAB}$. Our data show that glutamine can indeed rescue DAB-impaired memory when administered up to $2.5 \mathrm{~min}$ after training as well as during the second window for rescue 3055 min after training. At times when DAB does not inhibit, 

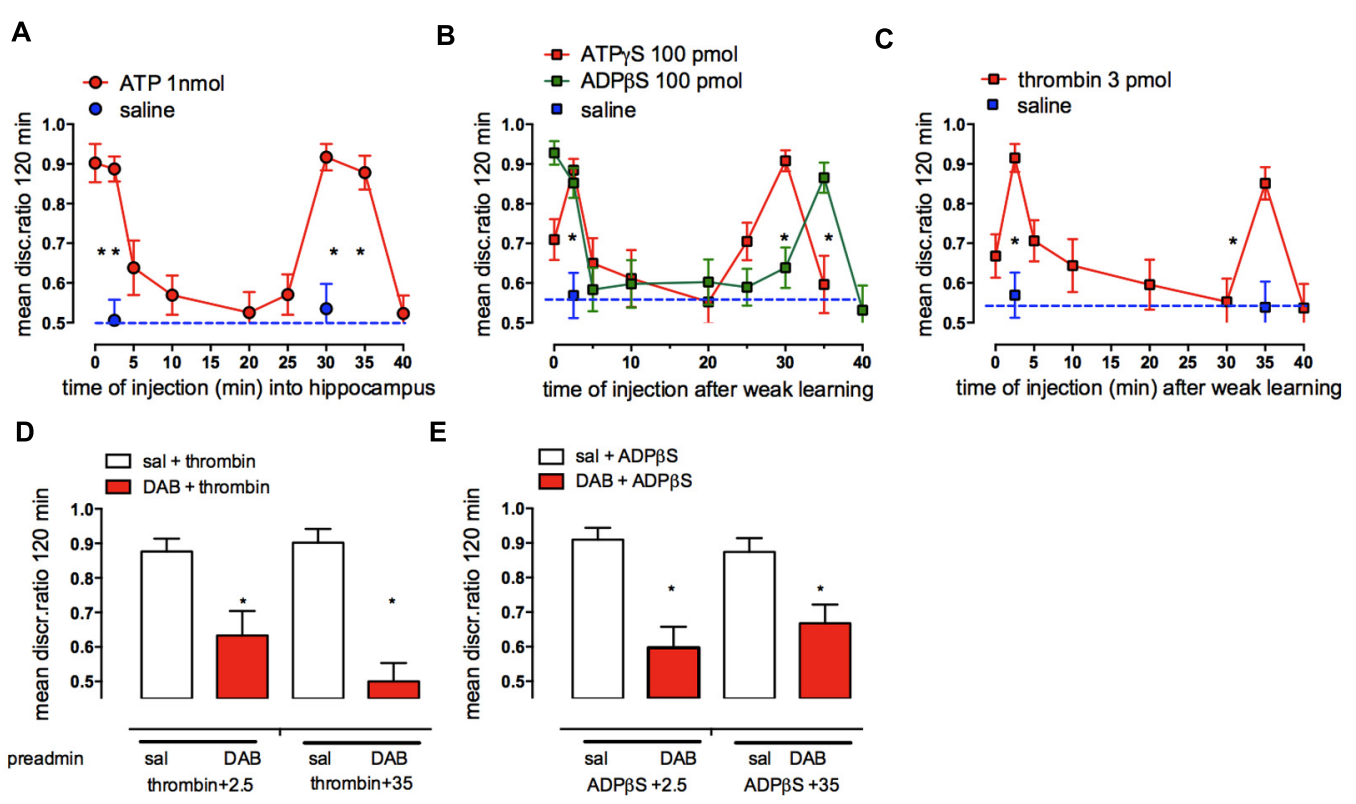

FIGURE 10 | Effect of hippocampal injection of ATP, ATP $\gamma$ S, ADP $\beta$, or thrombin (A-C) on consolidation of weakly reinforced training and the effect of DAB on the ability of thrombin, ADP $\boldsymbol{\beta}$ S to promote consolidation (D,E). Injections over two time periods after weakly reinforced training resulted in consolidation of memory 120 min after training. (A) ATP, (B) ADP $\beta S$ and ATP $\gamma$ S and (C) thrombin. (D,E) A sub-optimal dose of DAB (red columns) was injected subcutaneously 5 min before weakly reinforced training or 5 min before injection of thrombin or ADP $\beta S$ into the hippocampus 2.5 or 35 min after weakly reinforced training, i.e., at times when they normally promote consolidation (open columns). ${ }^{\star} P<0.05$. (From Gibbs et al., 2011).

i.e., when glycogen breakdown is not critical for memory consolidation (5-25 min) post-training glutamine does not rescue (Figure 11A) even though glutamine enhances weakly reinforced learning over this time period (5-30 min; Gibbs et al., 2006, 2007, 2008b). Additional experiments have shown that $\mathrm{DAB}$ is not successfully challenged by either aspartate or the astrocyte-specific metabolic substrate acetate alone. However, DAB-induced memory impairment can be rescued by acetate together with aspartate, with acetate needed as a precursor for the pyruvate carboxylase product oxaloacetate, because acetate alone cannot support pyruvate carboxylation (Gibbs et al., 2008b). These results suggest that a major function for glycogen during memory consolidation is to enable synthesis of glutamate and GABA via glutamate production in the astrocytes. This does not preclude that glycogen might also have a major role as a substrate for energy production. Moreover, both glutamate synthesis and its degradation are oxidative processes resulting in ATP production (Hertz et al., 2007). However, the relatively low rates of glycogenolysis in brain (Oz et al., 2012) should be kept in mind. Even the fast decline in glycogen occurring in the chick brain soon after training (Hertz et al., 2003) only amounts to $\sim 1.0 \mu \mathrm{mol} / \mathrm{min}$ per $\mathrm{g}$ wet $\mathrm{wt}$, which is similar to the stimulated rate of glucose utilization in rat brain (Hertz and Dienel, 2002). A major role for glycogen might also be to support the energetic needs of astrocytes, including those related to their signaling (DiNuzzo et al., 2012; Xu et al., 2013). If the role of extracellular lactate is, indeed, a signaling one (as suggested above), then glycogenolysis might also promote signaling to neurons.
Lactate also rescues DAB induced impairment of memory when injected either immediately after training or 10-20 min later (Figure 11B). So, in contrast to the action of glutamine, lactate rescues memory from loss caused by DAB only at times when memory is NOT susceptible to DAB. These are the same time periods over which lactate normally enhances weakly reinforced learning (5-20 min; Gibbs et al., 2008b). Because of the difference in timing of the effect of lactate and glutamine, it is unlikely that they are producing the same end result of increasing glutamate. Lactate is readily taken up by neurons and astrocytes, but lactate uptake into astrocytes inhibits glycolysis (Hertz et al., 2014a). In that paper we discussed the fluxes of lactate into astrocytes, neurons, and between astrocytes and the multifunctional roles for lactate. Transport of lactate between brain cells is mainly between astrocytes via gap junctions and release into extracellular space leads to significant exit of lactate from the brain via the blood and via the perivascular-lymphatic drainage system (Ball et al., 2010).

Many years ago we found evidence that inhibition of the Na,KATPase abolished memory (Mark and Watts, 1971; Gibbs and $\mathrm{Ng}, 1977)$. Recent experiments have suggested that $\beta_{2}$-adrenergic activity may partly alleviate the impaired memory in day-old chickens resulting from Na,K-ATPase inhibition (Hertz et al., 2015b). This would suggest involvement of the astrocytic Na,KATPase, which may require glycogenolysis for its function (DiNuzzo et al., 2010; Xu et al., 2013; Hertz et al., 2015b). Clearance of extracellular $\mathrm{K}^{+}$increases signal to noise ratio and thus is likely to play an important role in synaptic plasticity (and hence in triggering memory formation). 
A

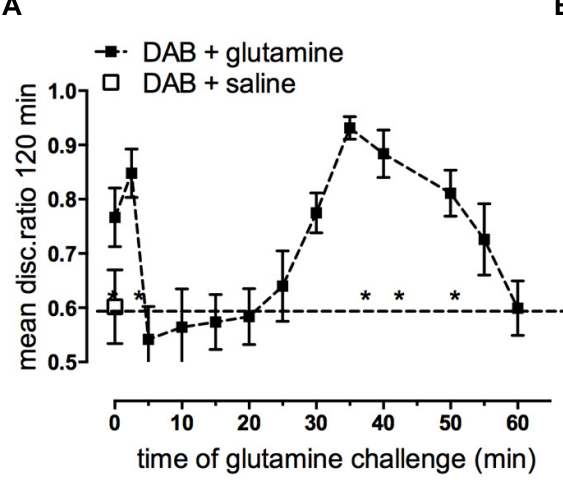

C

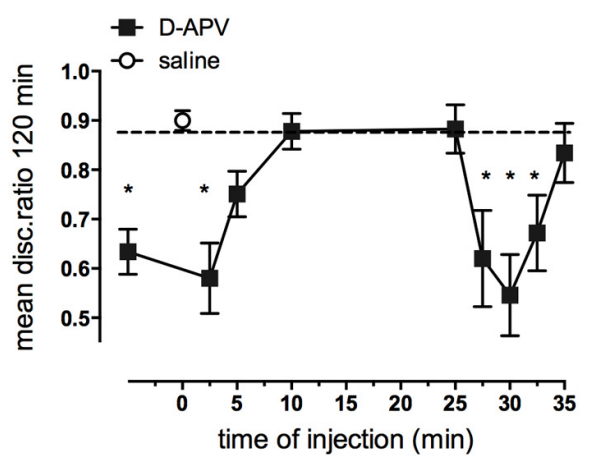

B

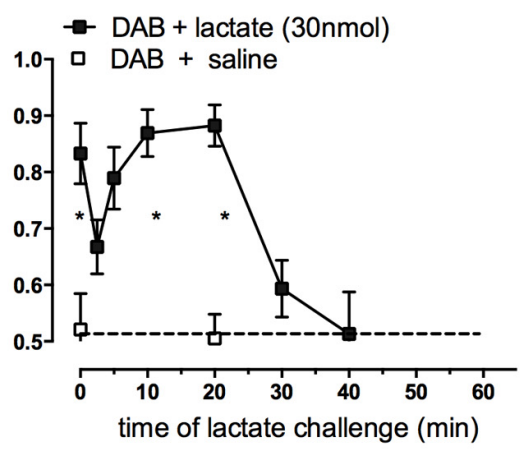

D

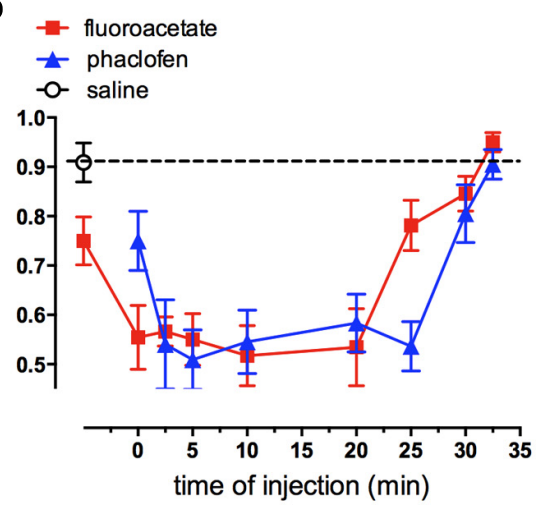

FIGURE 11 | Ability of glutamine or lactate to rescue memory following DAB inhibition of glycogenolysis (A,B) and effect of hippocampal injection of antagonists of NMDA receptors, GABA $A_{B}$ receptors or fluoroacetate on strongly reinforced training (C,D). DAB was injected into IMM 5 min before strongly reinforced training and challenged at various times by glutamine (A) or L-lactate (B) (From Hertz and Gibbs, 2009). (C) The NMDA angtagonist D-APV injected into the hippocampus inhibited memory given up to 5 min post-training and again when given 27.5-32.5 min post-training. (D) Both the $\mathrm{GABA}_{\mathrm{B}}$ receptor antagonist, phaclofen and fluoroacetate inhibited memory when given between 2.5 and 25 min post-training. ${ }^{*} P<0.05$. (From Gibbs et al., 2008a; Gibbs and Bowser, 2009).

\section{GLYCOGEN AS THE SUBSTRATE FOR DE NOVO SYNTHESIS OF GLUTAMATE AND GABA}

Both glutamate and GABA are involved in neurotransmission in the central nervous system and roles for glutamatergic NMDA (Figure 11C) and AMPA receptors (Gibbs et al., 2008a), mGluR and $\mathrm{GABA}_{B}$ (Gibbs and Bowser, 2009) receptors have been described for memory processing in the chick hippocampus. The importance of glutamate in memory formation up to $30 \mathrm{~min}$ post-training is highlighted by its effects at the two time periods $0-2.5$ and $25-30 \mathrm{~min}$, i.e., during STM and at the ITM transition from ITMA to ITMB. ATP and thrombin are similarly involved at these two times (Gibbs et al., 2011). A recent report has shown that DAB inhibition of glycogenolysis prevents LTP beyond $30 \mathrm{~min}$ in the rat hippocampus (Suzuki et al., 2011). We have shown above that one important reason why consolidation of memory is dependent on glycogenolysis is because of the brain's requirement for glutamate formation. However, both fluoroacetate (Figure 11D) and DAB (Figure 3D) injected into the hippocampus impair memory when given in between these times, implicating astrocytic activity and glycogenolysis over this period. The involvement of glycogen breakdown in memory is more extensive in the hippocampus than in the cortical IMM, and this may reflect on the requirement for astrocytes to supply GABA for interneurons. It is of interest that in IMM, fluoroacetate loses its inhibitory effect earlier than in the hippocampus and by $10 \mathrm{~min}$ after training it is ineffective in disrupting memory (Gibbs and Ng, 1977). GABA produced from glutamate is also dependent on glycogenolysis and inhibition of $\mathrm{GABA}_{\mathrm{B}}$ receptors by the selective antagonist phaclofen resulted in memory inhibition injected at all times between 2.5 and $25 \mathrm{~min}$ after training (Figure 11D; Gibbs and Bowser, 2009).

\section{WHY ASTROCYTES ARE REQUIRED FOR GLUTAMATE SYNTHESIS}

The reason neurons are unable to synthetize glutamate (and thus also GABA) and therefore are dependent upon glycogenolysismediated glutamate synthesis is that they lack an enzyme, pyruvate carboxylase, which is present in astrocytes (Yu et al., 1983; Shank et al., 1985) and most cell types outside the brain. Pyruvate carboxylase activity is required for direct conversion of 


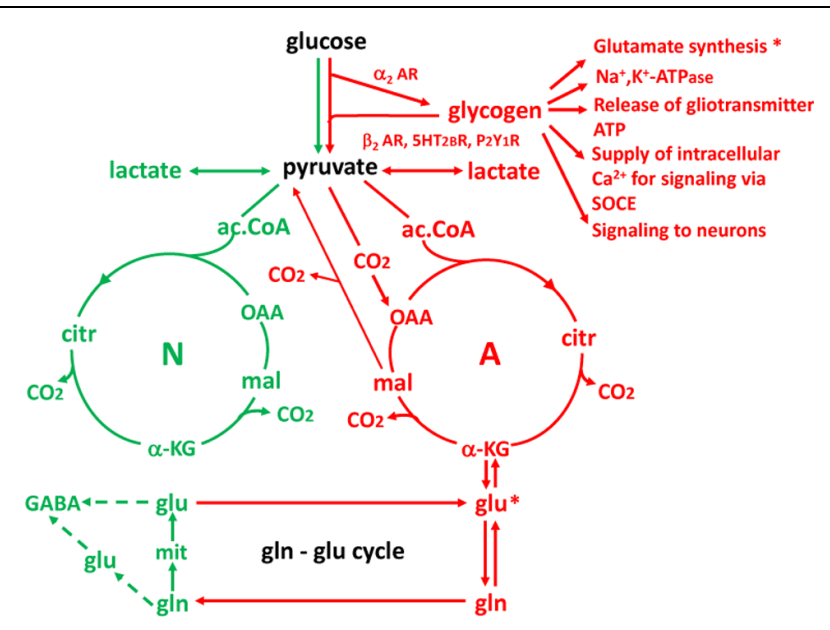

FIGURE 12 | Cartoon showing key features of glucose metabolism in neurons ( $\mathrm{N}$ and green) and astrocytes ( $\mathrm{A}$ and red) and interactions between the two cell types. Three reactions of importance in the present review are astrocyte-specific: (1) glycogenolysis (and thus its stimulation by noradrenergic, serotonergic and purinergic subtype-specific agonists); (2) formation of the tricarboxylic acid (TCA) cycle intermediate oxaloacetate (OAA) by condensation of pyruvate with $\mathrm{CO}_{2}$ (pyruvate carboxylation); and (3) formation of glutamine from glutamate by glutamine synthetase. Reaction (1) is important for the transmitter actions on memory and for glutamate synthesis documented in this review, and for partial alleviation by $\beta_{2}$-adrenergic activity of DAB-impaired memory resulting from Na,K-ATPase inhibition and inhibition of release of gliotransmitter ATP and of SOCE by DAB referred to. It is also important for release of lactate acting on neurons. Reaction (2) is essential for creation of a new molecule of a TCA cycle constituent OAA, allowing another molecule of a TCA cycle constituent, $\alpha-K G$ to leave the cycle and form glutamate. *Indicates the importance of glycogenolysis for glutamate synthesis and glutamate synthesis from $\alpha-K G$. And reaction (3) is a crucial step in supplying neurons with both newly synthesized and previously released glutamate. A fourth astrocyte-specific reaction is conversion of malate to pyruvate after its exit from the TCA cycle. This reaction allows metabolic degradation of accumulated glutamate but is not discussed in the review. The Figure should not give the impression that one half of brain energy metabolism is neuronal and one half astrocytic. Astrocytes account for a smaller fraction of the volume and therefore only for about one quarter of total glucose metabolism in gray matter (reviewed by Hertz, 2011), and other cell types like microglia also contribute to total energy metabolism.

pyruvate to oxaloacetate (OAA), which in turn is needed for the astrocytic production of glutamate (Figure 12). Metabolism of pyruvate by the pathway via acetyl coenzyme A (ac.CoA) which is used for energy production does not allow production of a new tricarboxylic acid (TCA) constituent because the two carbon atoms which are introduced into the TCA cycle with ac.CoA are released (providing energy) during its subsequent turn to OAA. Such a new molecule of a TCA cycle constituent is necessary for glutamate formation because glutamate is formed from another TCA cycle constituent, $\alpha$-ketoglutarate, $\alpha$-KG, which accordingly is removed from the cycle.

After its formation in astrocytes glutamate is converted by the astrocyte-specific glutamine synthetase (Norenberg and Martinez-Hernandez, 1979; Anlauf and Derouiche, 2013) to glutamine which is released from astrocytes and accumulated into neurons by specific, regulated transporters (Nissen-Meyer and Chaudhry, 2013) in the glutamine-glutamate cycle (glnglu cycle) and re-converted to glutamate and GABA (with slightly different pathways used in glutamatergic and GABAergic neurons). It should be emphasized that not all transmitter release depends on the de novo synthesis, since the transmitters are also re-utilized. However, especially glutamate is accumulated into astrocytes, not the neurons from which it was released, and again transferred to neurons after conversion to glutamine in astrocytes. This process accounts for $\sim 75 \%$ of the flux in the gln-glu cycle whereas the remaining $\sim 25 \%$ represents de novo synthesis (reviewed by Gibbs et al., 2008b; Hertz, 2013; Hertz and Rothman, 2015).

The similarly astrocyte-specific glycogenolysis (PfeifferGuglielmi et al., 2003) is also shown in Figure 12, and its correlation with glutamine synthesis indicated by asterisks, although it is probably not glutamate formation from $\alpha-K G$ but rather pyruvate carboxylation that requires glycogenolysis. This review has documented the importance of glycogenolysis for both glutamate formation and Na,K-ATPase activity and references have been made to its importance for release of gliotransmitter ATP and for supply of intracellular $\mathrm{Ca}^{2+}$ by store-operated $\mathrm{Ca}^{2+}$ entry (SOCE). Similarly, the possibility that glycogen-derived lactate may be an important signal to neurons has been discussed. Figure 12 summarizes these mechanisms (red text) as well as stimulation of glycogenolysis by $\beta_{2}-\mathrm{AR}$, $5-\mathrm{HT}_{2 \mathrm{~B}}$ receptors and $\mathrm{P} 2 \mathrm{Y} 1$ receptors and of glycogen synthesis by $\alpha_{2} \mathrm{AR}$, all documented in the review.

\section{CONCLUDING REMARKS}

The excitatory and inhibitory neurotransmitters, glutamate, and GABA, are mainly responsible for information transfer and communication between nerve cells, but it is the modulation of synaptic activity by neurotransmitters including noradrenaline, serotonin and ATP that determines whether information in short-term or intermediate memory is consolidated into permanent storage or allowed to fade. These neuromodulatory transmitters act via astrocytes, stimulating the breakdown of glycogen that enables the synthesis of glutamate and glutamine that is essential for maintaining normal neuronal levels of glutamate and GABA and also for the regulation of potassium homeostasis (Hertz et al., 2015a).

Serotonin is responsible for the glycogen breakdown required for the transition from STM to ITM 2.5 min after training and noradrenaline for the transition from intermediate to long-term memory $30 \mathrm{~min}$ after training. Even if glycogen's major role should be to provide energy, it clearly has another role in the brain where it is responsible for the synthesis of glutamine, the precursor for glutamate in neurons that are unable to synthesize glutamate de novo and most likely also for astrocytic $\mathrm{K}^{+}$uptake (Xu et al., 2013; Hertz et al., 2015a), which constitutes an essential component of $\mathrm{K}^{+}$homeostasis in the brain.

All noradrenergic input into the forebrain comes from cell bodies located in the locus coeruleus situated in the medulla. These fibres radiate out to brain areas including the hippocampus and the cortex where noradrenaline released acts on the 
noradrenergic receptors located on neurons, astrocytes, and microvessels and therefore can influence memory (Gibbs et al., 2010). The effect of noradrenaline on different cell types depends on the location of the different adrenergic receptors. The effects of noradrenergic stimulation on astrocytes, neurons and microglia, has been reviewed recently by O'Donnell et al. (2012).

In the avian cortex and hippocampus acts released noradrenaline acts on both $\beta_{2}$ and $\alpha_{2}$ adrenergic receptors to cause the breakdown and the re-synthesis of glycogen. It promotes the transition of intermediate to long-term memory, whereas serotonin-induced glycogenolysis is responsible for the earlier consolidation of STM to intermediate memory,

\section{REFERENCES}

Andersen, B., Rassov, A., Westergaard, N., and Lundgren, K. (1999). Inhibition of glycogenolysis in primary rat hepatocytes by 1, 4-dideoxy-1,4-imino-Darabinitol. Biochem. J. 342(Pt 3), 545-550. doi: 10.1042/0264-6021:3420545

Anlauf, E., and Derouiche, A. (2013). Glutamine synthetase as an astrocytic marker: its cell type and vesicle localization. Front. Endocrinol. 4:144. doi: 10.3389/fendo.2013.00144

Aoki, C. (1992). Beta-adrenergic receptors: astrocytic localization in the adult visual cortex and their relation to catecholamine axon terminals as revealed by electron microscopic immunocytochemistry. J. Neurosci. 12, 781-792.

Ball, K. K., Cruz, N. F., Mrak, R. E., and Dienel, G. A. (2010). Trafficking of glucose, lactate and amyloid-beta from the inferior colliculus through perivascular routes. J. Cereb. Blood Flow Metab. 30, 72-76. doi: 10.1038/jcbfm.2009.206

Bashir, Z. I., Bortolotto, Z. A., Davies, C. H., Berretta, N., Irving, A. J., Seal, A. J. M., et al. (1993). Induction of LTP in the hippocampus needs synaptic activation of glutamate metabotropic receptors. Nature 363, 347-350. doi: 10.1038/363347a0

Bergersen, L. H. (2015). Lactate transport and signaling in the brain: potential therapeutic targets and roles in body-brain interaction. J. Cereb. Blood Flow Metab. 35, 176-185. doi: 10.1038/jcbfm.2014.206

Bowser, D. N., and Khakh, B. S. (2004). ATP excites interneurons and astrocytes to increase synaptic inhibition in neuronal networks. J. Neurosci. 24, 8606-8620. doi: 10.1523/JNEUROSCI.2660-04.2004

Bowser, D. N., and Khakh, B. S. (2007). Vesicular ATP is the predominant cause of intercellular calcium waves in astrocytes. J. Gen. Physiol. 129, 485-491. doi: 10.1085/jgp.200709780

Brown, A. M. (2004). Brain glycogen re-awakened. J. Neurochem. 89, 537-552. doi: 10.1111/j.1471-4159.2004.02421.x

Brown, A. M., and Ransom, B. R. (2007). Astrocyte glycogen and brain energy metabolism. Glia 55, 1263-1271. doi: 10.1002/glia.20557

Burnstock, G. (2007). Physiology and pathophysiology of purinergic neurotransmission. Physiol. Rev. 87, 659-697. doi: 10.1152/physrev.00043.2006

Cambray-Deakin, M., Pearce, B., Morrow, C., and Murphy, S. (1988). Effects of neurotransmitters on astrocyte glycogen stores in vitro. J. Neurochem. 51, 1852-1857. doi: 10.1111/j.1471-4159.1988.tb01167.x

Chen, Y., Peng, L., Zhang, X., Stolzenburg, J. U., and Hertz, L. (1995). Further evidence that fluoxetine interacts with a 5-HT2C receptor in glial cells. Brain Res. Bull. 38, 153-159. doi: 10.1016/0361-9230(95)00082-P

Choi, I. Y., Seaquist, E. R., and Grutter, R. (2003). Effect of hypoglycemia on brain metabolism in vivo. J. Neurosci. Res. 72, 25-32. doi: 10.1002/jnr.10574

Cronin, C., Edwards, T. M., and Gibbs, M. E. (2011). Role for purinergic receptors in memory processing in young chicks. Behav. Brain Res. 223, 417-420. doi: 10.1016/j.bbr.2011.05.002

Cruz, N. F., and Dienel, G. A. (2002). High glycogen levels in brains of rats with minimal environmental stimuli: implications for metabolic contributions of working astrocytes. J. Cereb. Blood Flow Metab. 22, 1476-1489. doi: 10.1097/01.WCB.0000034362.37277.C0

Dai, H., Song, D., Xu, J., Li, B., Hertz, L., and Peng, L. (2013). Ammonia-induced $\mathrm{Na}, \mathrm{K}-\mathrm{ATPase} /$ ouabain-mediated EGF receptor transactivation, MAPK/ERK and PI3K/AKT signaling and ROS formation cause astrocyte swelling. Neurochem. Int. 63, 610-625. doi: 10.1016/j.neuint.2013.09.005 probably without any concomitant effect of serotonin on glycogen re-synthesis. This might explain why the level of glycogen is reduced $5 \mathrm{~min}$ after training (when serotonin mediates glycogenolysis) but not $30 \mathrm{~min}$ after training, when noradrenaline mediates glycogenolysis as well as glycogen synthesis (Figure 3A).

\section{AUTHOR CONTRIBUTIONS}

MG is the sole author of this review and which constitutes published work with a number of others.

Daisley, J. N., Gruss, M., Rose, S. P., and Braun, K. (1998). Passive avoidance training and recall are associated with increased glutamate levels in the intermediate medial hyperstriatum ventrale of the day-old chick. Neural Plast. 6, 53-61. doi: 10.1155/NP.1998.53

Daisley, J. N., and Rose, S. P. (2002). Amino acid release from the intermediate medial hyperstriatum ventral (IMHV) of day-old chicks following a onetrial passive avoidance task. Neurobiol. Learn. Mem. 77, 185-201. doi: 10.1006/nlme.2001.4011

Darvesh, A. S., and Gudelsky, G. A. (2003). Activation of 5-HT2 receptors induces glycogenolysis in the rat brain. Eur. J. Pharmacol. 464, 135-140. doi: 10.1016/S0014-2999(03)01432-8

Diaz, S. L., Doly, S., Narboux-Neme, N., Fernandez, S., Mazot, P., Banas, S. M., et al. (2012). 5-HT2B receptors are required for serotonin-selective andtidepressant actions. Mol. Psychiat 17, 154-163. doi: 10.1038/mp.2011.159

Dienel, G. A., Ball, K. K., and Cruz, N. F. (2007). A glycogen phosphorylase inhibitor selectively enhances local rates of glucose utilization in brain during sensory stimulation of conscious rats: implications for glycogen turnover. J. Neurochem. 102, 466-478. doi: 10.1111/j.1471-4159.2007. 04595.x

Dienel, G. A., Cruz, N. F., Ball, K., Popp, D., Gokden, M., Baron, S., et al. (2003). Behavioral training increases local astrocytic metabolic activity but does not alter outcome of mild transient ischemia. Brain Res. 961, 201-212. doi: 10.1016/S0006-8993(02)03945-8

DiNuzzo, M., Giove, F., Maraviglia, B., and Mangia, S. (2015). Monaminergic control of cellular glucose utilization by glycogenolysis in neorcortex and hippocampus. Neurochem. Res. 40, 2493-2504. doi: 10.1007/s11064-0151656-4

DiNuzzo, M., Mangia, S., Maraviglia, B., and Giove, F. (2010). Glycogenolysis in astrocytes supports blood-born glucose channeling not glycogen-derived lactate shuttling to neurons: evidence from mathematical modeling. J. Cereb. Blood Flow Metab. 30, 1895-1904. doi: 10.1038/jcbfm.2010.151

DiNuzzo, M., Mangia, S., Maraviglia, B., and Giove, F. (2012). The role of astrocytic glycogen in supporting the energetics of neuronal activity. Neurochem. Res. 37, 2432-2438. doi: 10.1007/s11064-012-0802-5

Du, T., Li, B., Liu, S., Zang, P., Prevot, V., Hertz, L., et al. (2009). ERK phosphorylation in intact, adult brain by alpha(2)-adrenergic transactivation of EGF receptors. Neurochem. Int. 55, 593-600. doi: 10.1016/j.neuint.2009. 05.016

Duran, J., Saez, I., Gruart, A., Guinovart, J. J., and Delgado-Garcia, J. M. (2013). Impairment in long-term memory formation and learning-dependent synaptic plasticity in mice lacking glycogen synthase in the brain. J. Cereb. Blood Flow Metab. 33, 550-556. doi: 10.1038/jcbfm.2012.200

Enkvist, M. O., Holopainen, I., and Akerman, K. E. (1989). Alpha-receptor and cholinergic receptor-linked changes in cystolic $\mathrm{Ca}^{2+}$ and membrane potential in primary rat astrocytes. Brain Res. 500, 46-54. doi: 10.1016/00068993(89)90298-9

Fields, R. D., and Burnstock, G. (2006). Purinergic signalling in neuron-glia interactions. Nat. Rev. Neurosci. 7, 423-436. doi: 10.1038/nrn1928

Fosgerau, K., Westergaard, N., Quistorff, B., Grunnet, N., Kristiansen, M., and Lundgren, K. (2000). Kinetic and functional characterization of 1,4-dideoxy1, 4-imino-d-arabinitol: a potent inhibitor of glycogen phosphorylase with 
anti-hyperglyceamic effect in ob/ob mice. Arch. Biochem. Biophys. 380, 274284. doi: 10.1006/abbi.2000.1930

Gibbs, M. E. (2008). Memory systems in the chick: regional and temporal control by noradrenaline. Brain Res. Bull. 76, 170-182. doi: 10.1016/j.brainresbull.2008.02.021

Gibbs, M. E., Anderson, D. G., and Hertz, L. (2006). Inhibition of glycogenolysis in astrocytes interrupts memory consolidation in young chickens. Glia 54, 214-222. doi: 10.1002/glia.20377

Gibbs, M. E., and Bowser, D. N. (2009). Astrocytes and interneurons in memory processing in the chick hippocampus: roles for G-coupled protein receptors, GABAB and mGluR1. Neurochem. Res. 34, 1712-1720. doi: 10.1007/s11064009-9980-1

Gibbs, M. E., and Bowser, D. N. (2010). Astrocytic adrenoceptors and learning: $\alpha 1$ adrenoceptors. Neurochem. Int. 57, 404-410. doi: 10.1016/j.neuint.2010.03.020

Gibbs, M. E., Bowser, D. N., Hutchinson, D. S., Loiacono, R. E., and Summers, R. J. (2008a). Memory processing in the avian hippocampus involves interactions between $\beta$-adrenoceptors, glutamate receptors, and metabolism. Neuropsychopharmacology 33, 2831-2846. doi: 10.1038/npp.2008.5

Gibbs, M. E., Hutchinson, D., and Hertz, L. (2008b). Astrocytic involvement in learning and memory consolidation. Neurosci. Biobehav. Rev. 32, 927-944. doi: 10.1016/j.neubiorev.2008.02.001

Gibbs, M. E., Hutchinson, D. S., and Summers, R. J. (2008c). Role of $\beta$-adrenoceptors in memory consolidation: beta3-adrenoceptors act on glucose uptake and beta2-adrenoceptors on glycogenolysis. Neuropsychopharmacology 33, 2384-2397. doi: 10.1038/sj.npp.1301629

Gibbs, M. E., Johnston, A. N., Mileusnic, R., and Crowe, S. F. (2008d). A comparison of protocols for passive and discriminative avoidance learning tasks in the domestic chick. Brain Res. Bull. 76, 198-207. doi: 10.1016/j.brainresbull.2008.02.032

Gibbs, M. E., and Hertz, L. (2008). Inhibition of astrocytic energy metabolism by D-lactate exposure impairs memory. Neurochem. Int. 52, 1012-1018. doi: 10.1016/j.neuint.2007.10.014

Gibbs, M. E., and Hertz, L. (2014). Serotonin mediation of early memory formation via 5-HT2B receptor-induced glycogenolysis in the day-old chick. Front. Pharmacol. 5:54. doi: 10.3389/fphar.2014.00054

Gibbs, M. E., and Hutchinson, D. S. (2012). Rapid turnover of glycogen in memory formation. Neurochem. Res. 37, 2456-2463. doi: 10.1007/s11064-012-0805-2

Gibbs, M. E., Hutchinson, D. S., and Summers, R. J. (2010). Noradrenaline release in the locus coeruleus modulates memory formation and consolidation Roles for $\alpha-\alpha \nu \delta \beta-\alpha \delta \rho \varepsilon \nu \varepsilon \rho \gamma \iota \chi \rho \varepsilon \chi \varepsilon \pi \tau о \rho \sigma$. Neuroscience 170, 1209-1222. doi: 10.1016/j.neuroscience.2010.07.052

Gibbs, M. E., Lloyd, H. G., Santa, T., and Hertz, L. (2007). Glycogen is a preferred glutamate precursor during learning in 1-day-old chick: biochemical and behavioral evidence. J. Neurosci. Res. 85, 3326-3333. doi: 10.1002/jnr. 21307

Gibbs, M. E., and Ng, K. T. (1977). Psychobiology of memory: towards a model of memory formation. Biobehav. Rev. 1, 113-136. doi: 10.1016/01477552(77)90017-1

Gibbs, M. E., Shleper, M., Mustafa, T., Burnstock, G., and Bowser, D. N. (2011). ATP derived from astrocytes modulates memory in the chick. Neuron Glia Biol. 7, 177-186. doi: 10.1017/S1740925X12000117

Gibbs, M. E., and Summers, R. J. (2002a). Role of adrenoceptor subtypesin memory consolidation. Prog. Neurobiol. 67, 345-391. doi: 10.1016/S03010082(02)00023-0

Gibbs, M. E., and Summers, R. J. (2002b). Effects of glucose and 2-deoxyglucose on memory formation in the chick: interaction with $\beta 3$-adrenoceptor agonists. Neuroscience 114, 69-79. doi: 10.1016/S0306-4522(02)00229-4

Gibbs, M. E., and Summers, R. J. (2005). Contrasting roles for $\beta 1, \beta 2$ and $\beta 3$ adrenoceptors in memory formation in the chick. Neuroscience 131, 31-42. doi: 10.1016/j.neuroscience.2004.10.036

Hertz, L. (2011). Astrocytic energy metabolism and glutamate formation-relevance for 13C-NMR spectroscopy and importance of cytosolic/mitochondrial trafficking. Magn. Reson. Imaging 29, 1319-1329. doi: 10.1016/j.mri.2011.04.013

Hertz, L. (2013). The Glutamate-Glutamine (GABA) Cycle: importance of late postnatal development and potential reciprocal interactions between biosynthesis and degradation. Front. Endocrinol. (Lausanne) 4:59. doi: $10.3389 /$ fendo.2013.00059
Hertz, L., and Dienel, G. A. (2002). "Energy metabolism in the brain," in Glucose Metabolism in the Brain, ed. D. S. Dwyer (SanDiego, CA: Academic Press, Inc.).

Hertz, L., Gerkau, N. J., Xu, J., Durry, S., Song, D., Rose, C. R., et al. (2015a). Roles of astrocytic $\mathrm{Na}^{+}, \mathrm{K}^{+}$-ATPase and glycogenolysis for $\mathrm{K}^{+}$homeostasis in mammalian brain. J. Neurosci. Res. 93, 1019-1039. doi: 10.1002/jnr.23499

Hertz, L., Song, D., Xu, J., Peng, L., and Gibbs, M. E. (2015b). Role of the astrocytic $\mathrm{Na}^{+}, \mathrm{K}^{+}$-ATPase in $\mathrm{K}^{+}$homeostasis in brain: $\mathrm{K}^{+}$uptake, signaling pathways and substrate utilization. Neurochem. Res. 40, 2505-2516. doi: 10.1007/s11064014-1505-x

Hertz, L., Xu, J., Song, D., Du, T., Li, B., Yan, E., et al. (2015c). Astrocytic glycogenolysis: mechanisms and functions. Metab. Brain Dis. 30, 317-333. doi: 10.1007/s11011-014-9536-1

Hertz, L., and Gibbs, M. E. (2009). What learning in day-old chickens can teach a neurochemist: focus on astrocyte metabolism. J. Neurochem. 109(Suppl. 1), 10-16. doi: 10.1111/j.1471-4159.2009.05939.x

Hertz, L., Gibbs, M. E., and Dienel, G. A. (2014a). Fluxes of lactate into, from, and among gap junction-coupled astrocytes and their interaction with noradrenaline. Front. Neurosci. 8:261. doi: 10.3389/fnins.2014.00261

Hertz, L., Xu, J., and Peng, L. (2014b). Glycogenolysis and purinergic signaling. Adv. Neurobiol. 11, 31-54. doi: 10.1007/978-3-319-08894-5_3

Hertz, L., Lovatt, D., Goldman, S. A., and Nedergaard, M. (2010). Adrenoceptors in brain: cellular gene expression and effects on astrocytic metabolism and [Ca++]I. Neurochem. Int. 57, 411-420. doi: 10.1016/j.neuint.2010. 03.019

Hertz, L., O’Dowd, B. S., Ng, K. T., and Gibbs, M. E. (2003). Reciprocal changes in forebrain contents of glycogen and of glutamate/glutamine during early memory consolidation in the day-old chick. Brain Res. 994, 226-233. doi: 10.1016/j.brainres.2003.09.044

Hertz, L., Peng, L., and Dienel, G. A. (2007). Energy metabolism in astrocytes: high rate of oxidative metabolism and spatiotemporal dependent on glycolysis/glycogenolysis. Cereb. Blood Flow Metab. 27, 219-249. doi: 10.1038/sj.jcbfm.9600343

Hertz, L., and Rothman, D. L. (2015). "Glucose, lactate, $\beta$-hydroxybutyrate, acetate, GABA, and succinate as substrates for synthesis of glutamate and GABA in the glutamine-glutamate/GABA cycle," in Advanced Neurobiology, eds U. Sonnewald and A. Schousboe (New York, NY: Springer).

Hertz, L., and Zielke, H. R. (2004). Astrocytic control of glutamatergic activity: astrocytes as stars of the show. Trends Neurosci. 27, 735-743. doi: 10.1016/j.tins.2004.10.008

Hutchinson, D. S., Catus, S. L., Merlin, J., Summers, R. J., and Gibbs, M. E. (2011). a2-Adrenoceptors activate noradrenaline-mediated glycogen turnover in chick astrocytes. J. Neurochem. 117, 915-926. doi: 10.1111/j.1471-4159.2011. 07261.x

Hutchinson, D. S., Summers, R. J., and Gibbs, M. E. (2008). Energy metabolism and memory processing: role of glucose transport and glycogen in responses to adrenoceptor activation in the chicken. Brain Res. Bull. 76, 224-234.

Jarvis, E. D., Gunturkun, O., Bruce, L., Csillag, A., Karten, H., Kuenzel, W., et al. (2005). Opinion; Avian brains and a new understanding of vertebrate brain evolution. Nat. Rev. Neurosci. 6, 151-159. doi: 10.1038/nrn1606

Kong, E. K., Peng, L., Chen, Y., Yu, A. C., and Hertz, L. (2002). Upregulation of 5 -HT2B receptor density and receptor-mediated glycogenolysis in mouse astrocytes by long-term fluoxetine administration. Neurochem. Res. 27, 113-120. doi: 10.1023/A:1014862808126

Lee, A., Rosin, D. L., and Van Bockstaele, E. J. (1998a). $\alpha 2 \mathrm{~A}$-adrenergic receptors in the rat nucleus locus coeruleus: subcellular localization in catecholaminergic dendrites, astrocytes, and presynaptic axon terminals. Brain Res. 795, 157-169. doi: 10.1016/S0006-8993(98)00266-2

Lee, A., Rosin, D. L., and Van Bockstaele, E. J. (1998b). Ultrastructural evidence for prominent postsynaptic localization of $\alpha 2 \mathrm{C}$-adrenergic receptors in catecholaminergic dendrites in the rat nucleus locus coeruleus. J. Comp. Neurol. 394, 218-229. doi: 10.1002/(SICI)1096-9861(19980504)394:2<218::AIDCNE6> 3.3.CO;2-Y

Li, B., Zhang, S., Zhang, H., Nu, W., Cai, L., Hertz, L., et al. (2008). Fluoxetine mediated 5-HT2B receptor stimulation in astrocytes causes EGF receptor transactivation and ERK phosphorylation. Psychopharmacology 201, 443-458. doi: 10.1007/s00213-008-1306-5

Lo, S., Russell, J. C., and Taylor, A. W. (1970). Determination of glycogen in small tissue samples. J. Appl. Physiol. 28, 234-236. 
Magistretti, P. J. (1988). Regulation of glycogenolysis by neurotransmitters in the central nervous system. Diabete Metab 14, 237-246.

Mark, R. F., and Watts, M. E. (1971). Drug inhibition of memory formation in chickens. I. Long-term memory. Proc. R. Soc. Lond. B. 178, 439-454. doi: 10.1098/rspb.1971.0074

Morgenthaler, F. D., Lanz, B. R., Petit, J. M., Frenkel, H., Magistretti, P. J., and Gruetter, R. (2009). Alteration of brain glycogen turnover in the conscious rat after $5 \mathrm{~h}$ of prolonged wakefulness. Neurochem. Int. 55, 45-51. doi: 10.1016/j.neuint.2009.02.023

Müller, M. S., Fox, R., Schousboe, A., Waagepetersen, H. S., and Bak, L. K. (2014). Astrocyte glycogenolysis is triggered by store-operated calcium entry and provides metabolic energy for cellular calcium homeostasis. Glia 62, 526-534. doi: $10.1002 /$ glia.22623

Newman, L. A., Korol, D. L., and Gold, P. E. (2011). Lactate produced by glycogenolysis in astrocytes regulates memory processing. PLoS ONE 6:e28427. doi: 10.1371 /journal.pone. 0028427

Nissen-Meyer, L. S., and Chaudhry, F. A. (2013). Protein kinase C phosphorylates the system $\mathrm{N}$ glutamine transporter SN1 (Slc38a3) and regulates its membrane trafficking and degradation. Front. Endocrinol. 4:138. doi: $10.3389 /$ fendo. 2013.00138

Norenberg, M. D., and Martinez-Hernandez, A. (1979). Fine structural localization of glutamine synthetase in astrocytes of rat brain. Brain Res. 161, 303-310. doi: 10.1016/0006-8993(79)90071-4

North, R. A., and Verkhratsky, A. (2006). Purinergic transmission in the central nervous system. Pflugers. Arch. 452, 479-485. doi: 10.1007/s00424-0060060-y

O’Donnell, J., Zeppenfeld, D., McConnell, E., Pena, S., and Nedergaard, M. (2012). Norepinephrine: a neuromodulator that boosts the function of multiple cell types to optimize CNS performance. Neurochem. Res. 37, 2496-2512. doi: 10.1007/s11064-012-0818-x

O’Dowd, B. S., Barrington, J., Ng, K. T., Hertz, E., and Hertz, L. (1995). Glycogenolytic response of primary chick and mouse cultures of astrocytes to noradrenaline across development. Dev. Br. Res. 88, 220-223. doi: 10.1016/0165-3806(95)00084-Q

O’Dowd, B. S., Gibbs, M. E., Ng, K. T., Hertz, E., and Hertz, L. (1994). Astrocytic glycogenolysis energizes memory processes in neonate chicks. Brain Res. Dev. Brain Res. 78, 137-141. doi: 10.1016/0165-3806(94)90018-3

Oz, G., Seaquist, E. R., Kumar, A., Criego, A. B., Benedict, L. E., Rao, J. P., et al. (2007). Human glycogen content and metabolism: implications on its role in brain energy metabolism. Am. J. Physiol. Endocrinol. Metab. 292, E946-E951. doi: 10.1152/ajpendo.00424.2006

Oz, G. H., Tesfaye, N., Kumar, A., Deelchand, D. K., Eberly, L. E., and Seaquist, E. R. (2012). Brain glycogen content and metabolism in subjects with type 1 diabetes and hypoglycemia unawareness. J. Cereb. Blood Flow Metab. 32, 256-263. doi: $10.1038 / \mathrm{jcbfm} .2011 .138$

Patel, A. B., Lai, J. C., Chowdhury, G. M., Hyder, F., Rothman, D. L., Shulman, R. G., et al. (2014). Direct evidence for activity-dependent glucose phosphorylation in neurons with implications for the astrocyte-to-neuron lactate shuttle. Proc. Natl. Acad. Sci. U.S.A. 111, 5385-5390. doi: 10.1073/pnas.1403 576111

Pellerin, L., and Magistretti, P. J. (2012). Sweet sixteen for ANLS. J. Cereb. Blood Flow Metab. 32, 1152-1166. doi: 10.1038/jcbfm.2011.149

Pellerin, L., Pellegri, G., Bittar, P. G., Charnay, Y., Bouras, C., Martin, J. L., et al. (1998). Evidence supporting the existence of an activity-dependent astrocyte-neuron lactate shuttle. Dev. Neurosci. 20, 291-299. doi: 10.1159/0000 17324

Pfeiffer-Guglielmi, B., Fleckenstein, B., Jung, G., and Hamprecht, B. (2003). Immunocytochemical localization of glycogen phosphorylase isozymes in rat nervous tissues by using isozyme-specific antibodies. J. Neurochem. 85, 73-81. doi: $10.1046 / j .1471-4159.2003 .01644 . x$

Puelles, L., Kuwana, E., Puelles, E., Bulfone, A., Shimamura, K., Keleher, J., et al. (2000). Pallial and subpallial derivatives in the embryonic chick and mouse telencephalon, traced by the expression of the genes Dlx-2, Emx-1, Nkx-2.1, Pax-6, and Tbr-1. J. Comp. Neurol. 424, 409-438. doi: 10.1002/10969861(20000828)424:3<409::AID-CNE3 > 3.0.CO;2-7

Quach, T. T., Duchemin, A. M., Rose, C., and Schwartz, J. C. (1988). $[3 \mathrm{H}]$ glycogenolysis in brain slices mediated by beta-adrenoceptors: comparison of physiological response and $[3 \mathrm{H}]$ dihydroalprenolol binding parameters. Neuropharmacology 27, 629-635. doi: 10.1016/0028-3908(88) 90185-2

Quach, T. T., Rose, C., Duchemin, A. M., and Schwartz, J. C. (1982). Glycogenolysis induced by serotonin in brain: identification of a new class of receptor. Nature 298, 373-375. doi: 10.1038/298373a0

Quach, T. T., Rose, C., and Schwartz, J. C. (1978). [3H]Glycogen hydrolysis in brain slices: responses to neurotransmitters and modulation of noradrenaline receptors. J. Neurochem. 30, 1335-1341. doi: 10.1111/j.1471-4159.1978.tb10464.x

Reiner, A., Perkel, D. J., Bruce, L. L., Butler, A. B., Csillag, A., Kuenzel, W., et al. (2004). Revised nomenclature for avian telencephalon and some related brainstem nuclei. J. Comp. Neurol. 473, 377-414. doi: 10.1002/cne. 20118

Riedel, G., Platt, B., and Micheau, J. (2003). Glutamate receptor function in learning and memory. Behav. Brain Res. 140, 1-47. doi: 10.1016/S01664328(02)00272-3

Rothman, D. L., De Feyter, H. M., de Graaf, R. A., Mason, G. F., and Behar, K. L. (2011). 13C MRS studies of neuroenergetics and neurotransmitter cycling in humans. NMR Biomed. 24, 943-957. doi: 10.1002/nbm. 1772

Scheinin, M., Lomasney, J. W., Hayden-Hixson, D. M., Schambra, U. B., Caron, M. G., Lefkowitz, R. J., et al. (1994). Distribution of alpha 2-adrenergic receptor subtype gene expression in rat brain. Brain Res. Mol. Brain Res. 21, 133-149. doi: 10.1016/0169-328X(94)90386-7

Shank, R. P., Bennett, G. S., Freytag, S. O., and Campbell, G. L. (1985). Pyruvate carboxylase: an astrocyte-specific enzyme implicated in the replenishment of amino acid neurotransmitter pools. Brain Res. 329, 364-367. doi: 10.1016/00068993(85)90552-9

Sibson, N. R., Dhankhar, A., Mason, G. F., Rothman, D. L., Behar, K. L., and Shulman, R. G. (1998). Stoichiometric coupling of brain glucose metabolism and glutamatergic neuronalactivity. Proc. Natl. Acad. Sci. U.S.A. 95, 316-321. doi: 10.1073/pnas.95.1.316

Sickmann, H. M., Waagepetersen, H. S., Schousboe, A., Benie, A. J., and Bouman, S. D. (2012). Brain glycogen and its role in supporting glutamate and GABA homeostasis in a type 2 diabetes rat model. Neurochem. Res. 60, 267-275. doi: 10.1016/j.neuint.2011.12.019

Sickmann, H. M., Walls, A. B., Schousboe, A., Bouman, S. D., and Waagepetersen, H. S. (2009). Functional significance of brain glycogen in sustaining glutamatergic neurotransmission. J. Neurochem. 109(Suppl. 1), 80-86. doi: 10.1111/j.1471-4159.2009.05915.x

Subbarao, K. V., and Hertz, L. (1990). Effect of adrenergic agonists on glycogenolysis in primary cultures of astrocytes. Brain Res. 536, 220-226. doi: 10.1016/0006-8993(90)90028-A

Suzuki, A., Stern, S. A., Bozdagi, O., Huntley, G. W., Walker, R. H., Magistretti, P. J., et al. (2011). Astrocyte-neuron lactate transport is required for long-term memory formation. Cell 144, 810-823. doi: 10.1016/j.cell.2011. 02.018

Swanson, R. A. (1992). Physiologic coupling of glial glycogen metabolism to neuronal activity in brain. Can. J. Physiol. Pharmacol. 70(Suppl.), S138-S144. doi: $10.1139 / \mathrm{y} 92-255$

Swanson, R. A., Morton, M. M., Sagar, S. M., and Sharp, F. R. (1992). Sensory stimulation induces local cerebral glycogenolysis: demonstration by autoradiography. Neuroscience 51, 451-461. doi: 10.1016/0306-4522(92) 90329-Z

Tadi, M., Allaman, I., Lengacher, S., Grenningloh, G., and Magistretti, P. J. (2015). Learning-induced gene expression in the hippocampus reveals a role of neuronastrocyte metabolic coupling in long term memory. PLOS ONE 10:e0141568. doi: 10.1371/journal.pone. 0141568

Tang, F., Lane, S., Korsak, A., Paton, J. F., Gourine, A. V., Kasparov, S., et al. (2014). Lactate-mediated glia-neuronal signalling in the mammalian brain. Nat. Commun. 5:3284 doi: $10.1038 /$ ncomms4284

Walling, S. G., Bromley, K., and Harley, C. W. (2006). Glycogen phosphorylase reactivity in the entorhinal complex in familiar and novel environments: evidence for labile glycogenolytic modules in the rat. J. Chem. Neuroanat. 31, 108-113. doi: 10.1016/j.jchemneu.2005.09.004

Watanabe, H., and Passonneau, J. V. (1973). Factors affecting the turnover of cerebral glycogen and limit dextrin in vivo. J. Neurochem. 20, 1543-1554. doi: 10.1111/j.1471-4159.1973.tb00272.x 
Xu, J., Song, D., Bai, Q., Zhou, L., Cai, L., Hertz, L., et al. (2014). Role of glycogenolysis in stimulation of ATP release from cultured mouse astrocytes by transmitters and high $\mathrm{K}^{+}$concentrations. ASN Neuro. 6:e00132. doi: 10.1042/AN20130040

Xu, J., Song, D., Xue, Z., Gu, L., Hertz, L., and Peng, L. (2013). Requirement of glycogenolysis for uptake of increased extracellular $\mathrm{K}^{+}$in astrocytes: potential implications for $\mathrm{K}^{+}$homeostasis and glycogen usage in brain. Neurochem. Res. 38, 472-485. doi: 10.1007/s11064-012-0938-3

Yu, A. C., Drejer, J., Hertz, L., and Schousboe, A. (1983). Pyruvate carboxylase activity in primary cultures of astrocytes and neurons. J. Neurochem. 41, 1484-1487. doi: 10.1111/j.1471-4159.1983.tb00849.x

Zorec, R., Araque, A., Carmignoto, G., Haydon, P. G., Verkhratsky, A., and Parpura, V. (2012). Astroglial excitability and gliotransmission : an appraisal of $\mathrm{Ca}^{2+}$ as a signalling route. ASN Neuro 42, 2505-2516. doi: 10.1042/AN20110061

Conflict of Interest Statement: The author declares that the research was conducted in the absence of any commercial or financial relationships that could be construed as a potential conflict of interest.

Copyright $\odot 2016$ Gibbs. This is an open-access article distributed under the terms of the Creative Commons Attribution License (CC BY). The use, distribution or reproduction in other forums is permitted, provided the original author(s) or licensor are credited and that the original publication in this journal is cited, in accordance with accepted academic practice. No use, distribution or reproduction is permitted which does not comply with these terms. 